\title{
Test and Analysis of Sub-Components of Aluminum-Lithium Alloy Cylinders
}

\author{
Waddy T. Haynie* \\ NASA Langley Research Center, Hampton, VA, 23681, USA \\ Prasad B. Chunchu ${ }^{\dagger}$ \\ Eagle Aeronautics, Inc., Hampton, VA, 23669, USA \\ Arunkumar Satyanarayana ${ }^{\ddagger}$ \\ ATK Space Systems, Inc., Hampton, VA, 23681, USA \\ Mark W. Hilburger ${ }^{\S}$ and Russell W. Smith \\ NASA Langley Research Center, Hampton, VA, 23681, USA
}

\begin{abstract}
Integrally machined blade-stiffened panels subjected to an axial compressive load were tested and analyzed to observe the buckling, crippling, and postcrippling response of the panels. The panels were fabricated from aluminum-lithium alloys 2195 and 2050 , and both alloys have reduced material properties in the short transverse material direction. The tests were designed to capture a failure mode characterized by the stiffener separating from the panel in the postbuckling range. This failure mode is attributed to the reduced properties in the short transverse direction. Full-field measurements of displacements and strains using three-dimensional digital image correlation systems and local measurements using strain gages were used to capture the deformation of the panel leading up to the failure of the panel for specimens fabricated from 2195. High-speed cameras were used to capture the initiation of the failure. Finite element models were developed using an isotropic strain-hardening material model. Good agreement was observed between the measured and predicted responses for both alloys.
\end{abstract}

\section{Introduction}

ESIGns of metallic launch vehicle structures, such as the Space Shuttle External Tank (ET), utilize integrally machined orthogrid stiffeners to reduce the weight of the structure. The ET is manufactured from aluminum-lithium (Al-Li) alloy 2195, which is a low density, high modulus aluminum alloy. One limitation of Al-Li 2195 is that properties degrade as the thickness of a rolled plate increases. To maintain allowable properties, plate thicknesses are limited to less than two inches. Al-Li alloy 2050, an alloy currently being studied for use in launch vehicle structures, is similar in composition to 2195 and can be made in plate thicknesses up to four inches without the degradation in material properties seen in 2195 for plates greater than two inches thick. For stability-critical structures, the additional plate thickness can result in more efficient stiffeners, which can reduce the weight of the structure. This study is an initial step in comparing the behavior of these two Al-Li alloys when used in integrally machined structural elements.

For both of these alloys the elongation at failure and fracture toughness in the short transverse (ST) material direction (the material direction through the thickness of the plate) are less than the respective properties in the plane of the plate. ${ }^{1}$ In tests of cylinders and panels that have continued loading into the

*Research Aerospace Engineer, Structural Mechanics and Concepts Branch, Mail Stop 190. Member, AIAA

${ }^{\dagger}$ Research Engineer, Structural Mechanics and Concepts Branch, Mail Stop 190. Member, AIAA

¥Senior Structural Analyst, Structural Mechanics and Concepts Branch, Mail Stop 190. Member, AIAA

$\S$ Research Aerospace Engineer, Structural Mechanics and Concepts Branch, Mail Stop 190. Senior Member, AIAA

『Research Aerospace Engineer, Structural Mechanics and Concepts Branch, Mail Stop 190. 
postbuckling range, failures have been observed that are characterized by the separation of the stiffener from the skin, referred to herein as a separation failure. Two examples of the separation failure in Al-Li alloy 2195 structures are shown in Figure 1, for a blade-stiffened panel of the same geometry as discussed in this paper, in Figure 1a, and for an orthogrid stiffened cylinder, in Figure 1b. In the panel and the cylinder, the separation failure occurred near the base of the stiffener, and is attributed to the reduced ST properties. Also in both cases, the separation failure occurred after buckling, and crippling (maximum load) in the case of the blade-stiffened panel; therefore, this type of failure may not typically be significant when designing structures manufactured from Al-Li alloys, as most designs do not allow buckling to occur. However, it is important to understand the physical mechanisms that initiate this type of failure so that if it is encountered either in future testing or in flight hardware, there will be knowledge of the behavior that precipitated the separation failure.

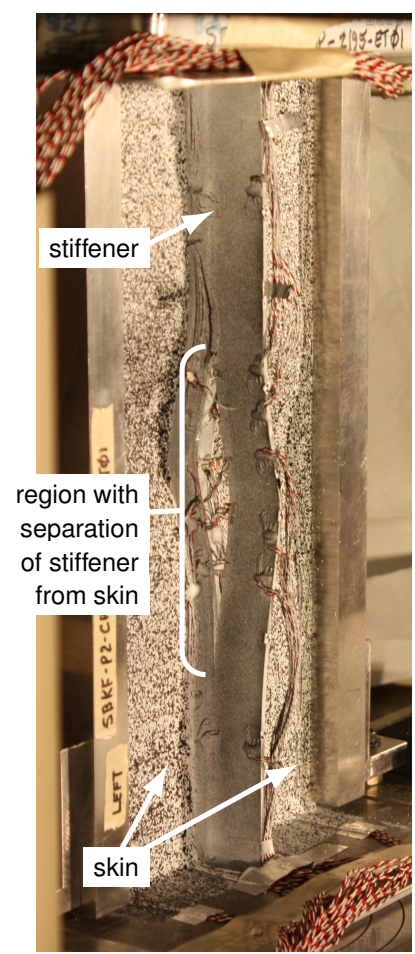

(a) blade-stiffened panel

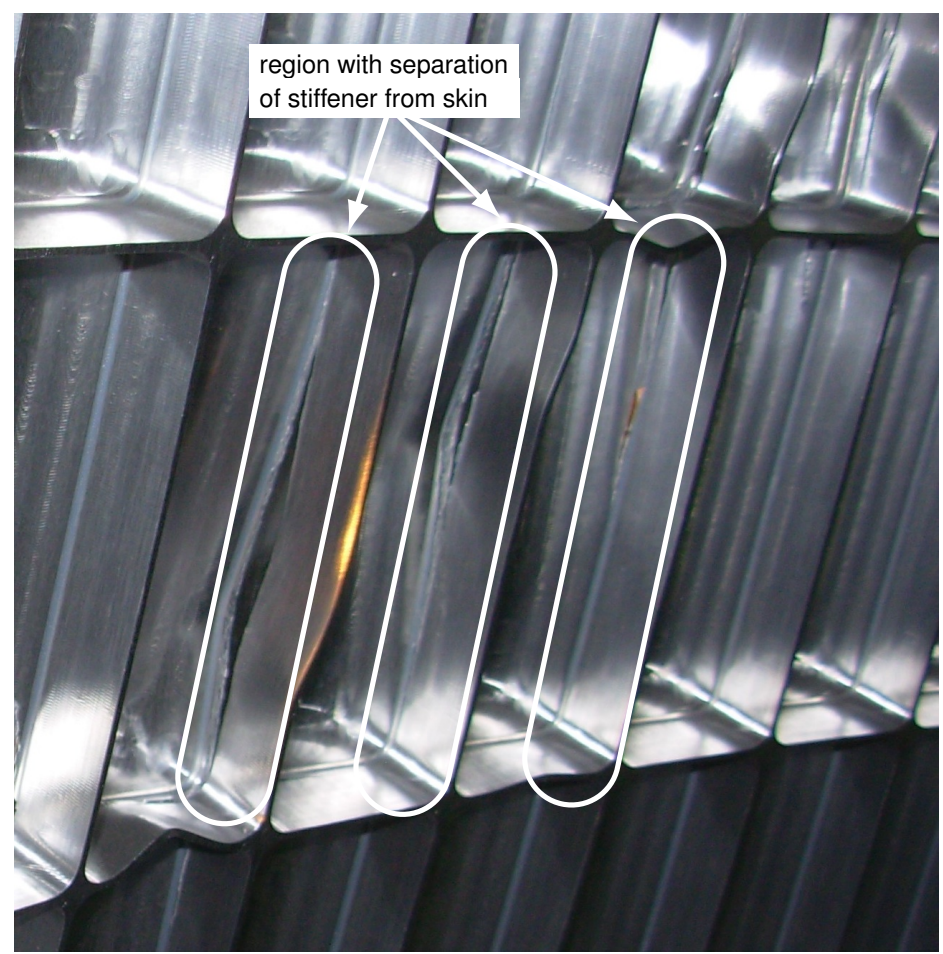

(b) cylinder

Figure 1. Examples of separation failures in structural testing

The objective of the current work is to test a series of integrally machined blade-stiffened panels fabricated from Al-Li 2195 and 2050, and use the test results to develop high-fidelity finite element models to be able to predict the response up to the initiation of the separation failure. Results from finite element analyses at their current level of fidelity are presented. Comparisons between the experimental results and the finite element results are made, and the next steps to further develop a high-fidelity finite element model to be able to predict the initiation of the separation failure are discussed.

\section{Test Specimens and Tests}

\section{A. Test Specimens}

Two specimens were fabricated from two-inch thick plate of both Al-Li alloy 2195 and 2050. The alloys have similar compositions. And both materials are anisotropic when considering the yield and failure properties. In particular, the elongation-to-failure in the short transverse material direction is approximately half of the elongation-to-failure in either the longitudinal or long transverse directions. ${ }^{1}$

The geometry of the test specimens is shown in Figure 2. Each specimen was fabricated so that the stiffener is aligned with the longitudinal material direction, as it would be if it were part of a larger orthogrid 
panel in a cylinder. The skin lies in the plane comprised by the longitudinal and long transverse material directions, and the stiffener extends from the skin in the short transverse material direction. The specimens have an overall length of $14 \mathrm{in}$. On both ends, one inch of the length of the specimen is potted in an epoxy grout, which is held in place by an aluminum frame. The area of the potted region is shown in Figure 2, and is used to enforce a clamped boundary condition. Considering the potting, the length of the test section is 12 in. The width of the panel is $5.5 \mathrm{in}$., with the integrally machined stiffener at the center of the skin section. The skin has a thickness of $0.095 \mathrm{in}$. The stiffener height is $0.95 \mathrm{in}$., and its thickness is $0.088 \mathrm{in}$. The fillet radius at the junction of the stiffener and the skin is $0.125 \mathrm{in}$. Stiffener geometry was taken from a typical design of an ET cylinder. Width of the panel was determined from a previous set of specimens in which the effects of panel width were studied. The current width was chosen because it was expected to minimize the variability of the location at which the initiation of the separation failure could occur. As will be described below, reducing this variability, allowed for some of the image systems to be focused on a smaller area of the specimen as a means of increasing the resolution of the systems. To ensure uniform loading, the ends of the specimen were machined flat and parallel.

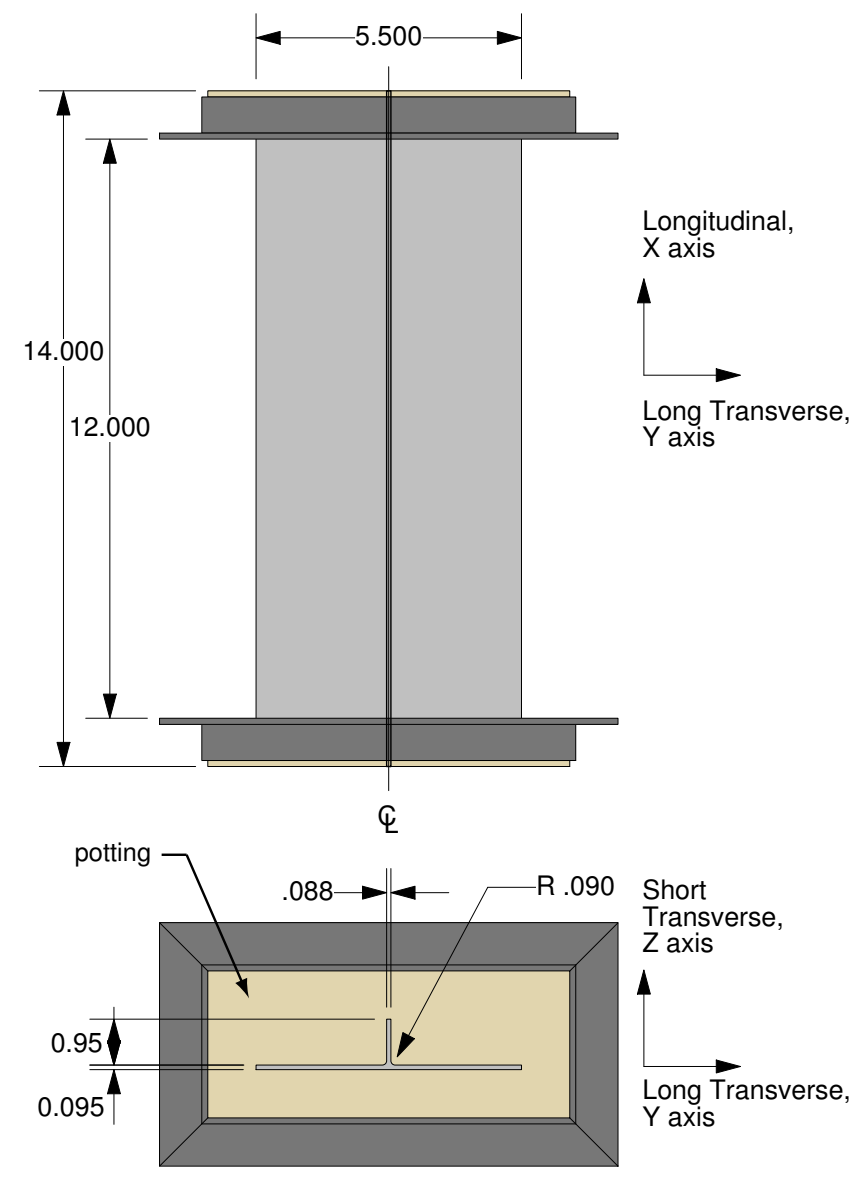

Figure 2. Specimen geometry (all units in in.)

In preparation for testing, electrical-resistance strain gages were installed at the locations indicated in Figure 3. Each location is identified by a letter, and at all locations the strain gage shown is one of a back-to-back pair, e.g., for gage A shown on the stiffener side of the panel there is another gage A on the opposite side of the skin, or skin side of the panel. Similarly for gage O shown on the right side of the stiffener there is another gage $\mathrm{O}$ on the left side of the stiffener. Except for gages $\mathrm{M}$ and $\mathrm{N}$, the strain gages on the skin are uniaxial strain gages measuring strain in the longitudinal material direction. Gages M and $\mathrm{N}$ are biaxial gages measuring the strain in the longitudinal and long transverse directions. All strain gages on the stiffener are biaxial gages measuring strains in the longitudinal and short transverse directions. 


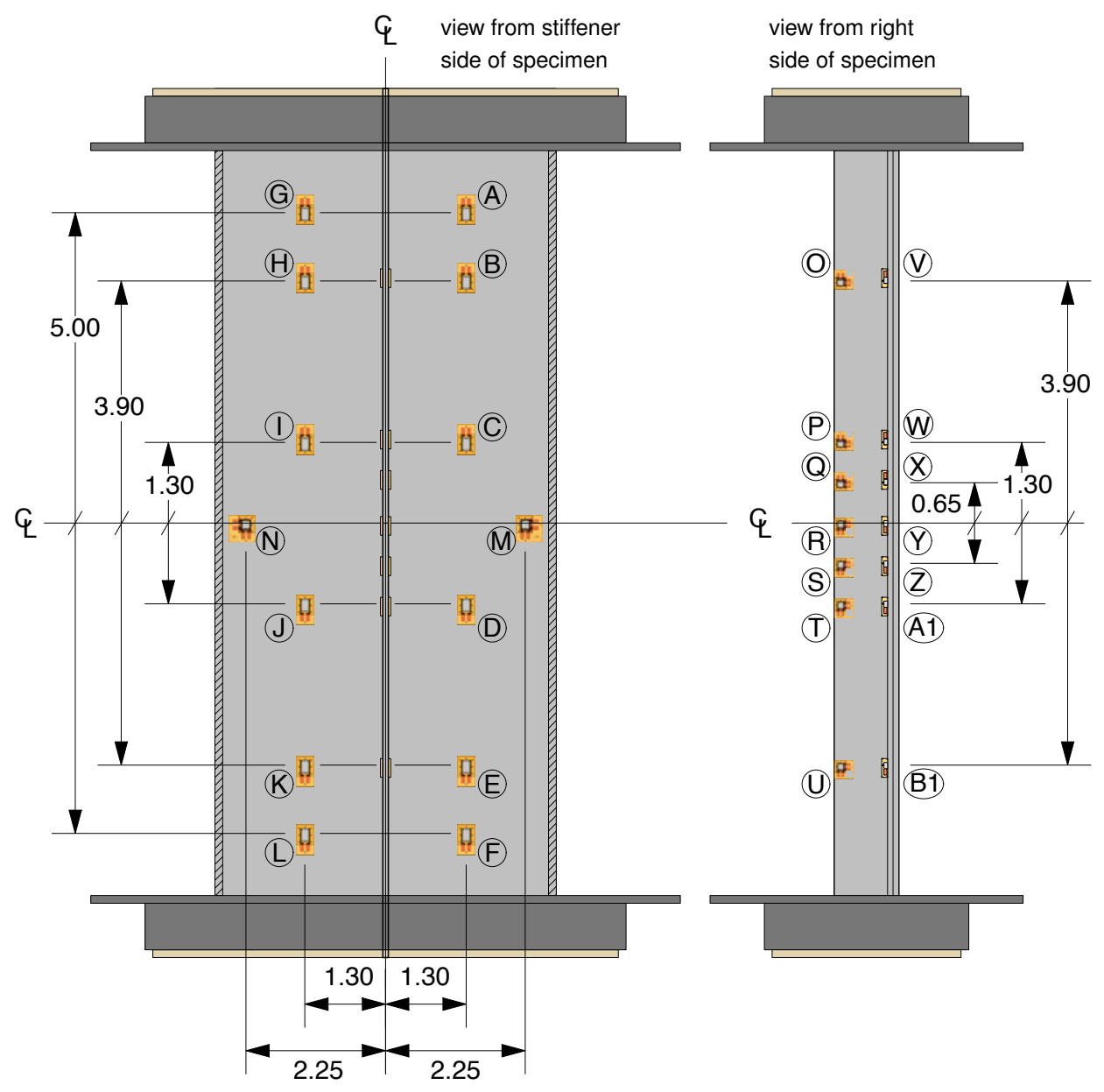

Figure 3. Strain gage pattern (all units in in.)

A black-and-white speckle pattern was painted on the specimen to use with the digital image correlation (DIC) systems. Patterns of two different speckle sizes and densities were used. A coarser pattern with larger speckles was used on the skin than on the stiffener, because as will be described below, the DIC systems used to measure the global skin response were measuring the entire length and width of the skin and the DIC systems measuring the stiffener response considered only a local area near the mid-length. Bow-tie markers were also applied to the edge the stiffener near the axial strain gage locations corresponding to gages $\mathrm{O}$ through $\mathrm{U}$. These markers were used to track the lateral displacements of the edge of the stiffener. Knife-edge supports were also installed on each of the unloaded edges of the skin to restrain out-of-plane displacement of the skin edges, and were installed 0.125 in. in from the skin edge.

\section{B. Experimental Set-Up}

All test were conducted in a 120-kip hydraulic testing machine. All specimens were loaded at a rate of approximately $2000 \mathrm{lb} / \mathrm{min}$. Three linear variable displacement transducers (LVDTs) were used to measure the relative movement (displacement and rotation) of the loading platens of the test machine. The LVDT measurements were used to determine the axial end displacement of the specimen, and the rotations of the platen during testing. Load, displacement, and strain data was acquired at a rate of $2 \mathrm{~Hz}$.

Four digital image correlation (DIC) systems were used in the tests. Two systems were used to measure the global response of the skin with one on the stiffener side and the other on the skin side of the specimen. The DIC system on the stiffener side was also used to track several bow-tie markers that were glued to the edge of the stiffener. The axial locations of the markers corresponded to the axial strain gage locations of gages $\mathrm{O}$ through $\mathrm{U}$ on the stiffener. The other two DIC systems were local systems used to measure the 
response on the left and right sides of the stiffener near the mid-length of the specimen where the separation failure was expected to initiate. Images were acquired at a rate of $1 \mathrm{~Hz}$ by the DIC systems.

Two high-speed digital video cameras were used to capture the initiation and progression of the separation failure. One camera was focused on the left side of the stiffener, and the other on the right side of the stiffener. The fields of view of the cameras contained the entire height of the stiffener and a portion of the skin, but only approximately one-third of the length of the stiffener. These cameras operated with a post-trigger, and a recording rate of 15,000 frames per second was used.

\section{Finite Element Models and Analyses}

The finite element models of the blade stiffened panels in this study were built using MSC Patran $2011,{ }^{2}$ and the analyses were performed with Abaqus/Standard $6.11 .^{3}$ A representative finite element mesh and a detailed view of the cross section of the mesh near the base of the stiffener are shown in Figure 4 . The geometry of the model is the same as is given in Figure 2. The model is comprised of 236,600 C3D8R three-dimensional solid elements. The approximate element size is $0.04 \mathrm{in} . \times 0.04 \mathrm{in} . \times 0.025 \mathrm{in}$. for elements in the skin and stiffener that are not in the fillet region. The element size varies in the fillet region at the base of the stiffener, as can be seen in Figure 4b, to accommodate for the fillet geometry and the change in the cross sectional aspect ratio from the elements in the skin to the elements in the stiffener.

Boundary conditions are applied to simulate the compression loading, the area of the specimen embedded in the potting, and the knife edge supports. At one end of the model, $x=14 \mathrm{in}$., all three degrees of freedom for the nodes are fixed. On the other end, $x=0$ in., only the degrees of freedom in the $\mathrm{Y}$ and $\mathrm{Z}$ directions are fixed and the degree of freedom in the $\mathrm{X}$ direction is free to translate. During the analysis an end displacement is applied to this end of the panel, and all nodes are constrained to move the same distance. The potting is modeled ideally, with the out-of-plane displacements of both the skin and stiffener, respectively, restrained for a 1-in. region at both ends of the specimen. The knife-edge restraints are modeled by restraining the skin out-of-plane displacements ( $\mathrm{Z}$ direction displacements) for the nodes on the outer surfaces 0.125 in., $y$ $= \pm 2.625$ in., in from the edge of the skin, but the degrees of freedom are free in the $\mathrm{X}$ and $\mathrm{Y}$ directions.

Several material models were considered during the present

Table 1. Elastic material properties study. Elastic, elastic-perfectly plastic, and elastic-strain hardening material models were used. All considered the material to be

\begin{tabular}{|c|c|c|}
\hline Material & $\begin{array}{c}\text { Elastic } \\
\text { Modulus, } \\
\text { Msi }\end{array}$ & $\begin{array}{c}\text { Poisson's } \\
\text { Ratio }\end{array}$ \\
\hline 2195 & 10.8 & 0.33 \\
\hline 2050 & 11.1 & 0.33 \\
\hline
\end{tabular}
isotropic. Best agreement between the experimental and analytical results was obtained with the isotropic elastic-strain hardening model, and in the proceeding discussion only the elastic-strain hardening model is considered. Typical stress-strain relationships for compression in the longitudinal material direction for 2195 and $2050^{4}$ were used to determine the stress-strain relationship for each material. An elastic modulus and Poisson's ratio were used to define the elastic stress-strain response and these are summarized for 2195 and 2050 in Table 1. Stresses and plastic strains are used to define the strain hardening portion of the material response. The stress and plastic strain values used in the analyses of 2195 and 2050 specimens are given in Tables 2 and 3, respectively. The values in Tables 2 and 3 were determined from typical compressive stress-strain curves for the longitudinal material direction for the respective material. Then using a linear fit for a portion of the linear elastic part of the curve, the stress at which the stress-strain curve starts to deviate from the linear fit was used as the initial value for the strain hardening data. After determining the initiation, strains were found at regular intervals of stress to determine the strain hardening response. In Abaqus, for magnitudes of strain larger than those defined for either material in Tables 2 and 3, the material is considered perfectly plastic with a stress level corresponding to the last stress level of the strain hardening data.

Two types of analyses were used to predict the response of the specimen. First, linear buckling analyses were used to predict the buckling mode shape. Second, a nonlinear static analysis was used to predict the response of the specimen under a uniform axial end displacement. The predicted mode shape from the first analysis was used as an initial imperfection in the second analysis, and an imperfection amplitude of $0.1 \%$ of the skin thickness was used. 
Table 2. Data for strain hardening stress-strain curve for Al-Li 2195

\begin{tabular}{|c|l|}
\hline $\begin{array}{c}\text { Stress, } \\
\text { ksi }\end{array}$ & $\begin{array}{c}\text { Plastic } \\
\text { Strain, } \varepsilon\end{array}$ \\
\hline 60.0 & 0.0 \\
\hline 62.5 & 0.00003 \\
\hline 65.2 & 0.00011 \\
\hline 67.5 & 0.00018 \\
\hline 70.0 & 0.00033 \\
\hline 72.5 & 0.00064 \\
\hline 75.0 & 0.00098 \\
\hline 77.5 & 0.00152 \\
\hline 80.0 & 0.0026 \\
\hline 82.5 & 0.0044 \\
\hline 85.0 & 0.0074 \\
\hline 87.5 & 0.0132 \\
\hline 87.9 & 0.0143 \\
\hline
\end{tabular}

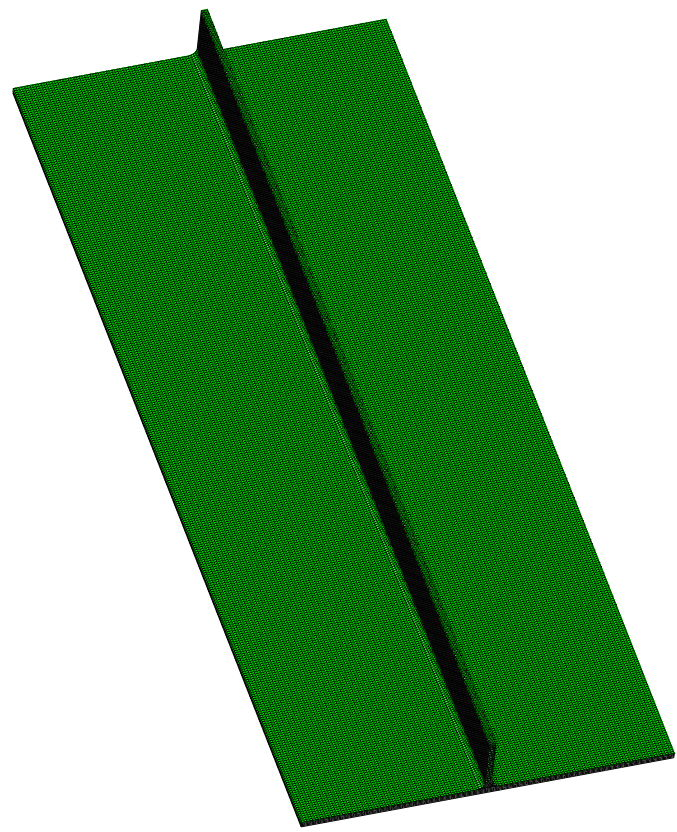

(a) full mesh
Table 3. Data for strain hardening stress-strain curves for Al-Li 2050

\begin{tabular}{|c|l|}
\hline $\begin{array}{c}\text { Stress, } \\
\text { ksi }\end{array}$ & $\begin{array}{c}\text { Plastic } \\
\text { Strain, } \varepsilon\end{array}$ \\
\hline 54.0 & 0.0 \\
\hline 56.0 & 0.000006 \\
\hline 58.0 & 0.000041 \\
\hline 60.0 & 0.00011 \\
\hline 62.0 & 0.00027 \\
\hline 64.0 & 0.00051 \\
\hline 66.0 & 0.00101 \\
\hline 68.0 & 0.00175 \\
\hline 70.0 & 0.0030 \\
\hline 72.0 & 0.0053 \\
\hline 74.0 & 0.0124 \\
\hline 74.2 & 0.0163 \\
\hline
\end{tabular}

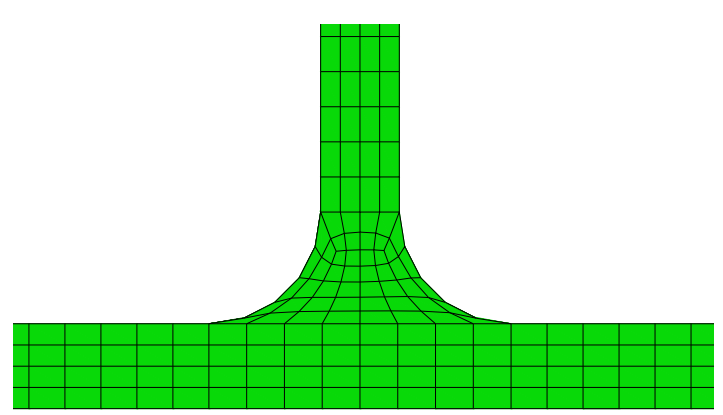

(b) cross section near base of stiffener

Figure 4. Finite element representation 


\section{Test and Analysis Results and Discussion}

In the following subsections, the results of the tests of blade-stiffened panels fabricated from Al-Li 2195 and 2050 are discussed. Results from instrumentation, such as load cells, LVDT's, and strain gages, as well as DIC systems and high speed cameras are used to present the response of the panels, and how the response leads to the initiation of the stiffener separation failure. In conjunction with the test results, the results from the analyses are presented, and the correlation between the test and analysis is discussed.

\section{A. Al-Li 2195 specimens}

The two Al-Li 2195 specimens were subjected to an axial compressive load until the separation failure occurred in both specimens. These specimens are denoted herein as 2195-01 and 2195-02. The load-end displacement responses for the two specimens and the corresponding finite element analysis are shown in Figure 5. The end displacements for the specimens were adjusted so the slope of the linear portion of the load-end displacement response aligned with the slope from the analysis. Adjusting the end displacement by a constant value accounts for the nonlinearity in the load-end displacement response due to the settling of the test article in the test frame. The specimens buckle, cripple, and ultimately fail when the stiffener separates from the skin, and the loads at which these occur are summarized in Table 4. Here the crippling load was the maximum load incurred during the test. An approximate buckling load was determined using the stiffener out-of-plane displacements measured with the DIC system by tracking the displacement of the bow tie markers on the stiffener. Linear curve fits of the prebuckling and initial postbuckling portions

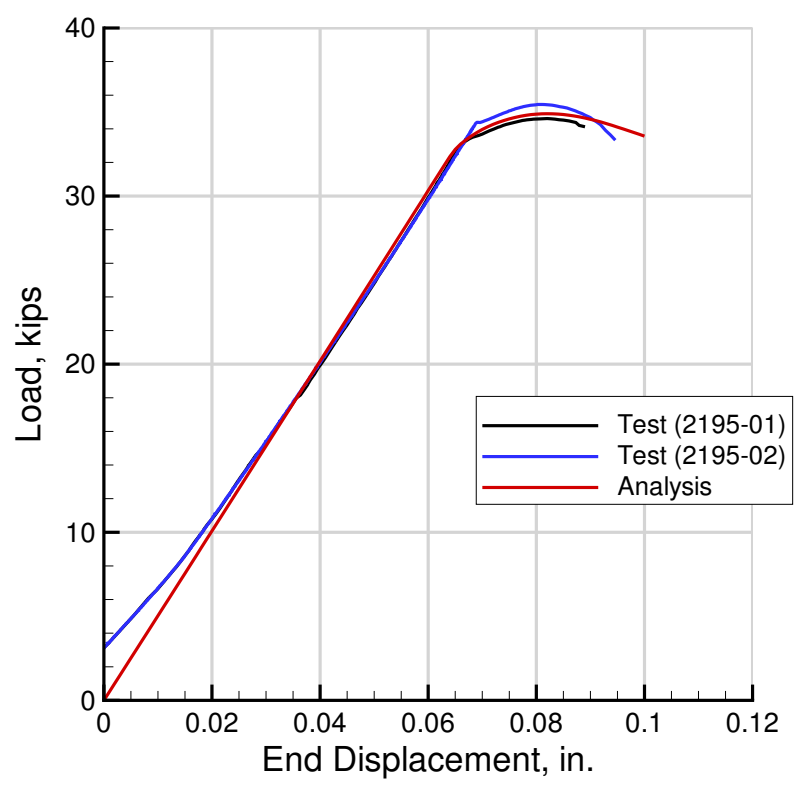

Figure 5. Load vs. end displacement response for 2195 specimens of the response were extrapolated to find an intersecting point, which was considered the buckling load. Also included in Table 4 are the end displacements at which the separation failure occurs in the test specimens. A failure criterion was not included in the analysis, so the values included for the end of the tests are for when the analysis was stopped. The analysis was stopped at an end displacement of 0.1 in., because that end displacement was greater than the end displacement at failure for either of the test specimens.

Table 4. Loads and end displacements from tests and analysis of Al-Li 2195 specimens

\begin{tabular}{|l|c|c|c|}
\hline & $2195-01$ & $2195-02$ & Analysis \\
\hline buckling load, kips & 32.7 & 34.3 & 32.4 \\
\hline crippling load, kips & 34.6 & 35.4 & 34.9 \\
\hline load at end of test, kips & 34.1 & 33.3 & $33.6^{*}$ \\
\hline end displacement at end of test, in. & 0.089 & 0.095 & $0.1^{*}$ \\
\hline
\end{tabular}

*Values when analysis was stopped, failure was not accounted for in analysis.

There is good agreement between the tests and analysis when comparing the values summarized in Table 4. The buckling, crippling, and failure loads for specimens 2195-01 and 2195-02 were within 5\% of each other. The buckling load for the analysis was within $1 \%$ and $6 \%$ of the buckling loads for 2195-01 and $2195-02$, respectively. Also, the crippling load for the analysis was within $1 \%$ and $2 \%$ of the crippling loads for 2195-01 and 2195-02, respectively. To compare the failure load from the tests to the analysis, the load from the analysis at the end displacements at which failure occurred in the tests was used. In the analysis the 
loads at end displacements of 0.089 and 0.095 in. were 34.6 and 34.1 kips, respectively. For this comparison the load from the analysis was within $2 \%$ and $3 \%$ of the loads at failure for 2195-01 and 2195-02, respectively.

Full-field out-of-plane displacements of the skin are shown using color contours to represent the buckling mode in Figure 6 and the deformed shape at the end of the test from the stiffener side and skin side in Figures 7 and 8 , respectively. In these figures positive displacements are in the direction of the stiffener, with the largest positive displacements represented by red; and negative displacements are in the direction away from the stiffener, with the largest negative displacements represented by the dark blue (predicted results) or purple (DIC measurements). In the tests and analyses, the skin and stiffener buckling modes had four half waves along the length. The half waves closer to the midlength had larger amplitudes than the half waves nearer the ends of the test section, and this is indicated by larger areas of red and blue/purple contours near the midlength. Specimen 2195-02 buckled into a shape with a negative amplitude compared to 2195-01 and the analysis. At the end of the tests and analysis, the deformation shape had developed to where the half waves near the midlength that buckled in the direction away from the stiffener had significantly larger amplitudes than the other half waves, as indicated by the blue and purple contours in Figures 7 and 8 . Also, at the nodes between half waves, the skin behind the stiffener had deflected out of plane, as shown in Figure 8 , where blue contours from a half wave on one side of the stiffener extend diagonally across the skin behind the stiffener to a half wave on the other side of the stiffener. This type of deflection, seen earlier in the postbuckling range, was an indication of crippling of the specimen. Prior to crippling the stiffener was effectively a boundary between the two sections of skin.

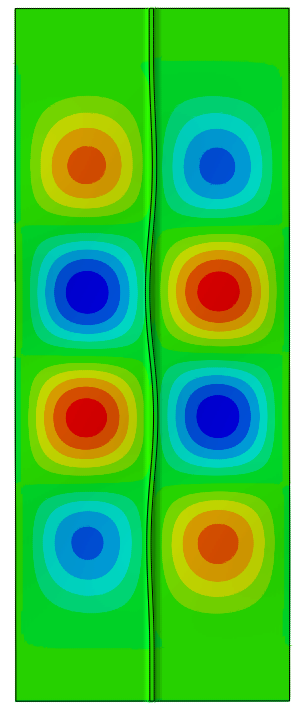

(a) predicted

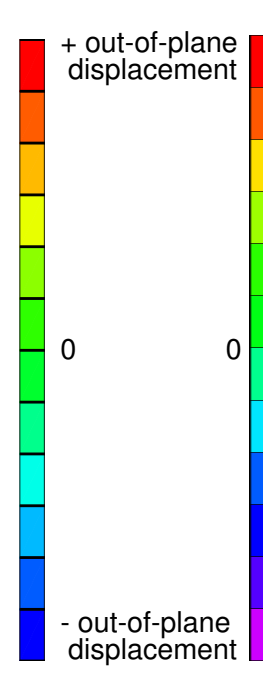

Figure 6. Buckling shapes for 2195 specimens

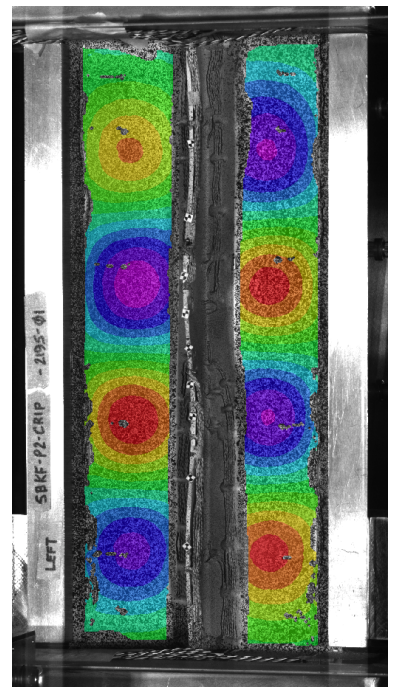

(b) measured, 2195-01

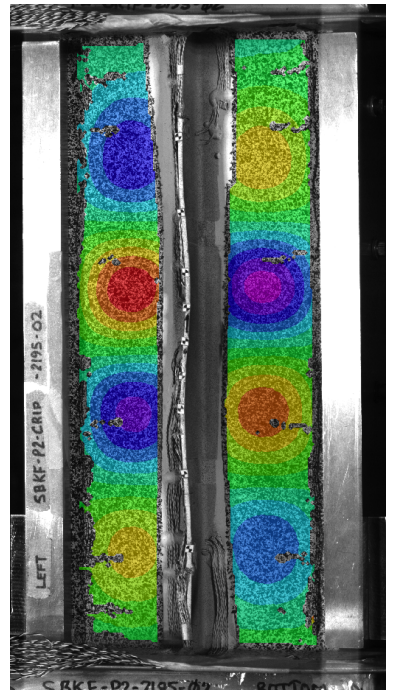

(c) measured, 2195-02

The separation failure initiated at a stress concentration that developed in the stiffener during postbuckling response. For specimen 2195-02 the strain gages on the right side of the stiffener were removed prior to the test so the gages and wires would not disrupt the correlated area for the DIC system. Removing the strain gages and wires also made it easier to see the initiation of the separation failure. The stiffener out-of-plane displacement, strain in the short transverse direction, or transverse strain, and the axial strain for the last image acquired before the separation failure occurred in 2195-02 are shown in Figure 9. The same results at the end of the analysis are shown in Figure 10. The stiffener out-of-plane displacement as measured from the local DIC system on the right side of the stiffener is shown in Figure 9a, and the bow tie markers are denoted by the respective gage location for each. The transverse and axial strains as measured from the DIC systems on the right side of the stiffener are shown in Figures 9b and 9c, respectively, and the approximate gage locations are denoted at the base of the stiffener where the gages were before being removed. As the stiffener deflected out of plane in the postbuckling response, an area of high tensile strain in the short transverse direction and high compressive strain in the longitudinal direction developed. This area was at the base of the stiffener, near where the fillet radius starts, and there was similar behavior on the other side of the stiffener. On the right side of the stiffener, the area was between gage locations $\mathrm{Y}$ and $\mathrm{Z}$. 


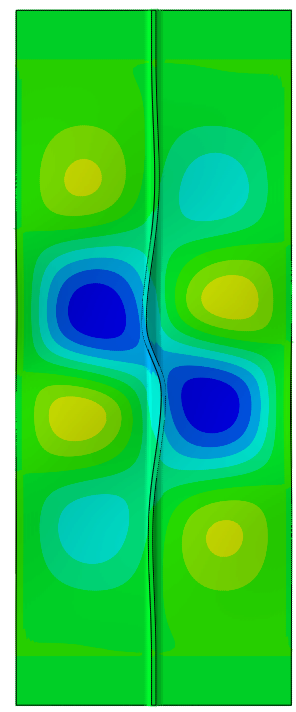

(a) predicted
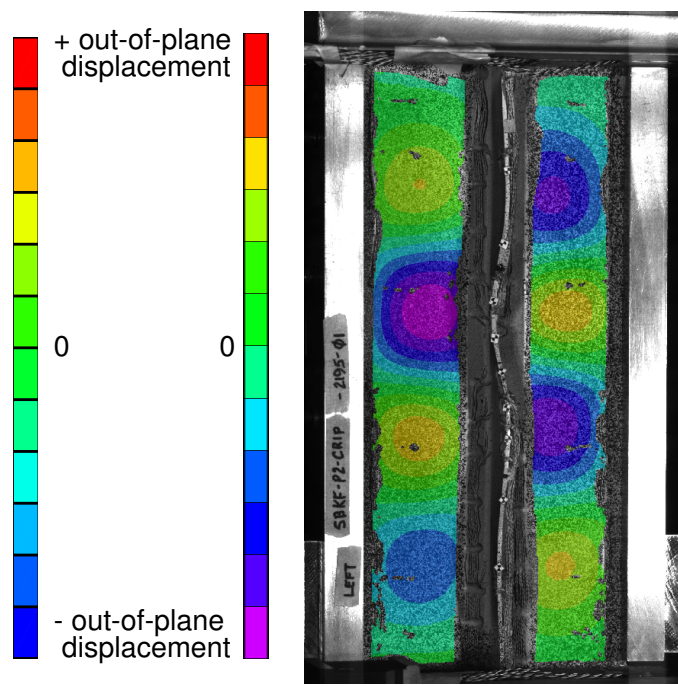

(b) measured, 2195-01

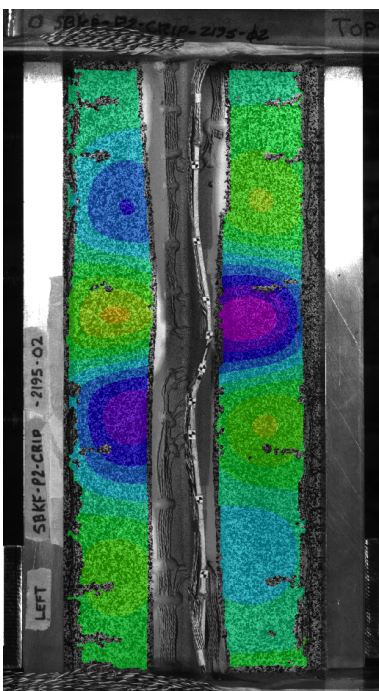

(c) measured, 2195-02

Figure 7. Prefailure shapes for 2195 specimens (view from stiffener side)

On the left side of the stiffener, this area was between gage locations $\mathrm{X}$ and Y. Similar areas of high tensile strain in the short transverse direction and high compressive strain in the longitudinal direction were seen in the analysis as well; however, due to the difference in the buckling shape between the analysis (Figures $6 \mathrm{a}$ and 10a) and specimen 2195-02 (Figures 6c and 9a) the area of high tensile strain on the left side of the stiffener was between gage locations $\mathrm{Y}$ and $\mathrm{Z}$, and on the right side, between gage locations $\mathrm{X}$ and $\mathrm{Y}$.

Examining images from the high speed cameras for 2195-02 show the separation failure initiated from the area of high tensile transverse strain between gage locations X and Y. Images after the initiation of the separation failure in 2195-02 are shown for the high speed cameras on the right side of the stiffener in Figure 11. Only images from the right side of the stiffener are shown because it was much easier to see the crack in still images, however, the crack initiation and growth appeared simultaneously on the left side of the stiffener. A small crack, indicating the location of the onset of the separation failure, is encircled in Figure 11a. Note the location of the crack is near the base of the stiffener where the area of high tensile strain was seen in Figure 9 (although in this case it is on the opposite side of the stiffener). After approximately $1.5 \mathrm{~ms}$, the separation had progressed along slightly less than half of the length of the test section, as shown in Figure 11d. The separation also started to tunnel through the fillet toward the skin as the propogation of the separation stopped. The initiation of the separation failure occurred between gage locations $\mathrm{Y}$ and $\mathrm{Z}$ for 2195-01.

In the above discussion, test and analysis results were compared in qualitative terms regarding the full-field displacement and strain measurements of the specimen. In the following discussion, comparisons of selected point displacement and strain gage measurements will be made to assess the correlation of the analysis with the test. Only results from 2195-01 will be used since 2195-02 buckled into a negative amplitude shape compared to 2195-01 and the analysis. The load-stiffener lateral displacement responses are shown in Figure 12a for gage locations $\mathrm{O}$ and $\mathrm{P}$, and Figure 12b for gage locations $\mathrm{T}$ and $\mathrm{U}$. Gage locations $\mathrm{O}, \mathrm{P}$, $\mathrm{T}$, and $\mathrm{U}$ correspond approximately to the peaks of the half waves of the buckling mode. At all locations, there is little or no stiffener deflection in the prebuckling range, and then there are significant displacements once buckling occurs. As observed in the out-of-plane displacements for the skin, the displacements for the half waves closer to the midlength, corresponding to locations $\mathrm{P}$ and $\mathrm{T}$, had larger displacements than those closer to the ends. When comparing the test results to the analysis, there was good qualitative agreement in the stiffener lateral displacements. Some differences would be expected since the analysis was continued to an end displacement approximately $10 \%$ greater than the end displacement at failure for 2195-01. Other differences could be attributed to material, geometric, or loading imperfections that were not considered in the analysis.

To compare the agreement between the measured and predicted strains, the strains near the region 


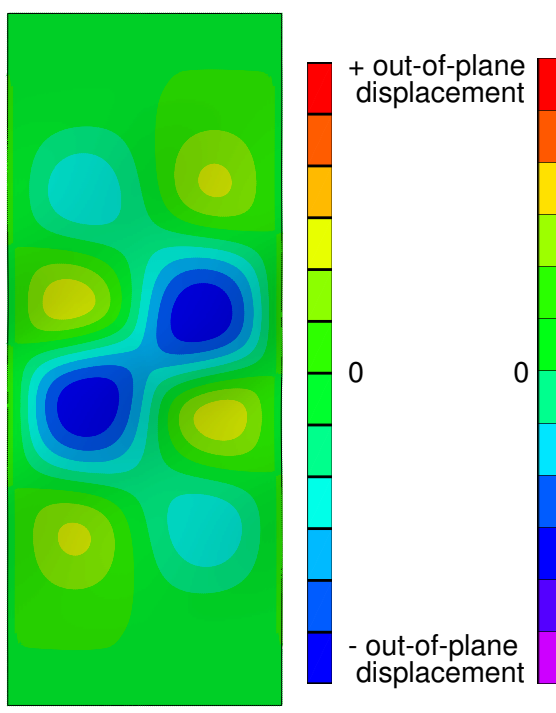

(a) predicted

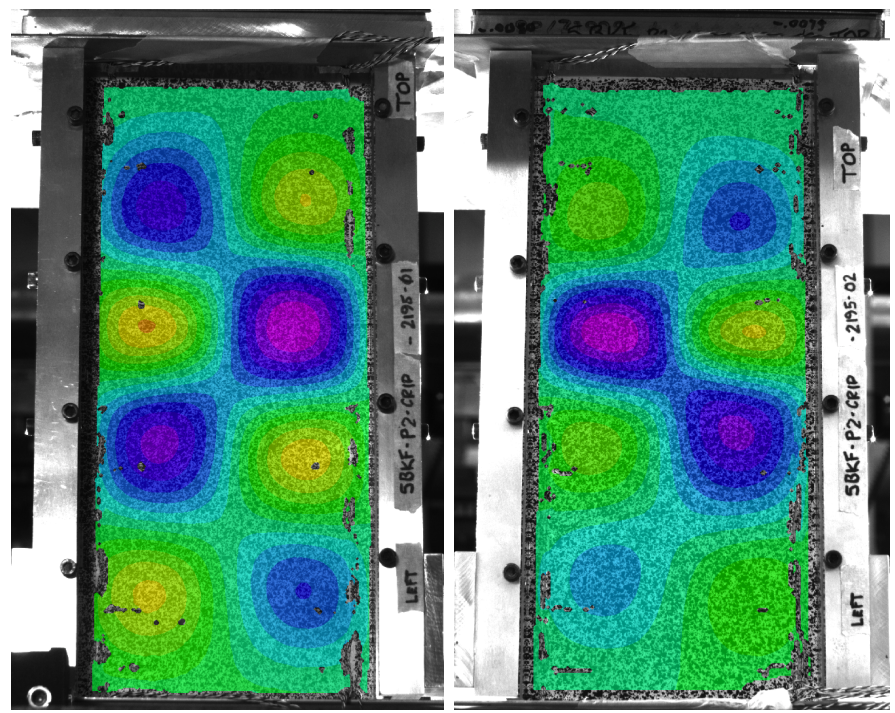

(b) measured, 2195-01

(c) measured, 2195-02

Figure 8. Prefailure shapes for 2195 specimens (view from skin side)

where the separation failure was initiated are considered. Specifically, when comparing the strains in the longitudinal and short transverse directions at the base of the stiffener and at strain gage locations $\mathrm{W}$, $\mathrm{X}, \mathrm{Y}, \mathrm{Z}$, and A1, there was good agreement between the test and analysis results. Load-strain responses for these gage locations are shown in Figures 13-17. In the prebuckling range for the strains in the short transverse direction, herein referred to as transverse strains, the positive strains were a result of Poisson expansion since the loading was in the longitudinal direction. Once buckling occurred and the stiffener began to deflect, transverse strains on one side of the stiffener continued increasing and on the other side started decreasing. At both gage locations $\mathrm{W}$ and $\mathrm{A} 1$, transverse strains from the analysis reverse near the end of the analysis, which was consistent with the decreasing magnitude of stiffener lateral displacements at locations $\mathrm{P}$ and $\mathrm{T}$ shown in Figures $12 \mathrm{a}$ and $12 \mathrm{~b}$. This strain reversal is not seen in the strains for the specimen, and could be an indication that plasticity has been induced in the specimen but not in the analysis.

Strains at locations $\mathrm{X}, \mathrm{Y}$, and Z, the gage locations closest to the areas of high tensile strain in the short transverse direction like those shown in Figure 9, predict a response more in agreement with what was observed in the test than at locations $\mathrm{W}$ and $\mathrm{A} 1$ where the strain reversal was observed. This response is shown in the load-strain responses at gage locations X in Figure 14, Y in Figure 15, Z in Figure 16, and A1 in Figure 17. For the strain at gage location Y, the strain in the short transverse direction was an increasing tensile strain on both sides of the stiffener in both the test and the analysis. This was a result of location $\mathrm{Y}$ being at a node between half waves in the postbuckling shape. As with the stiffener out-of-plane displacements, larger magnitudes of strain were expected in the analysis response due to the larger applied end displacement.

Overall, for the level of detail currently included in the model, there was good agreement between the test and the analysis when considering the out-of-plane displacements of the skin and lateral displacements in the stiffener as well as strains in the stiffener near the area where the initiation of the separation failure occurred. Based upon strains measured using strain gages and DIC systems, and from observing the crack initiation and growth with the high speed cameras, a strain state similar to the one observed during the test was seen in the finite element model. Improvements in the model could be made by including details such as an initial geometric imperfection based on pretest measurements, loading imperfections, or an anisotropic yield model. However, to complete the modeling effort a failure criterion to predict the initiation of the crack would be necessary. 


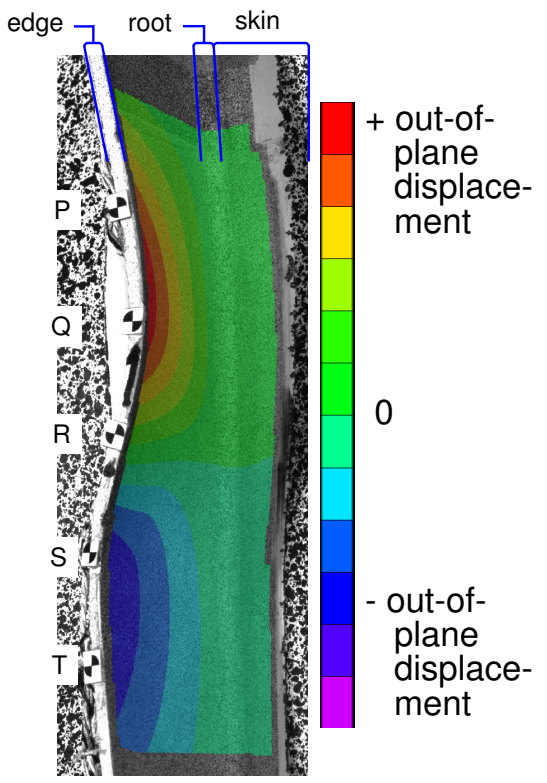

(a) out-of-plane displacement

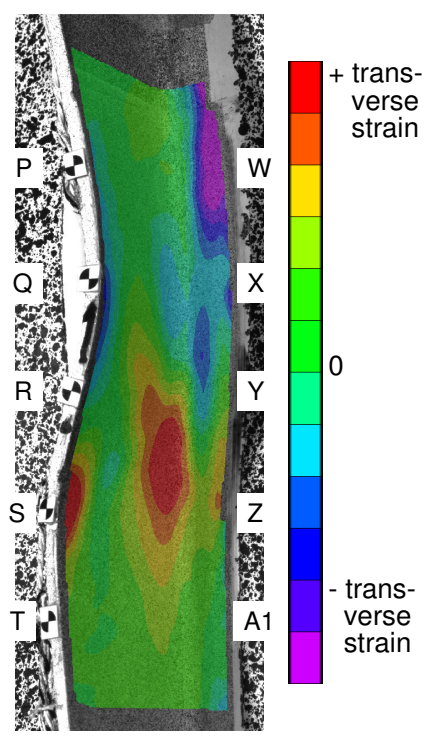

(b) transverse strain

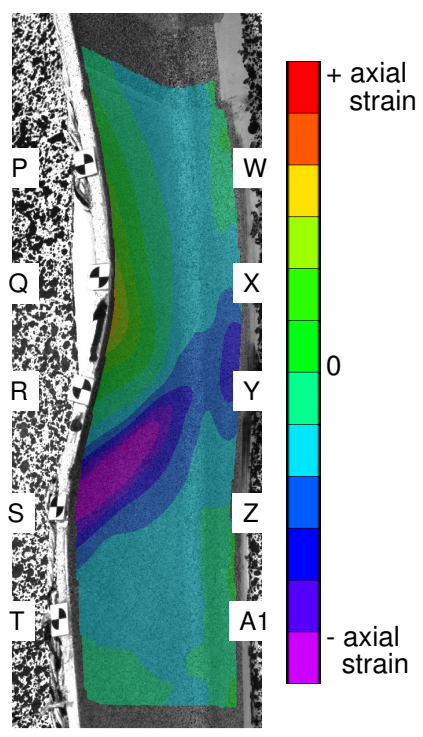

(c) axial strain

Figure 9. Measurements at end of test from local DIC system on right side of stiffener for 2195-02

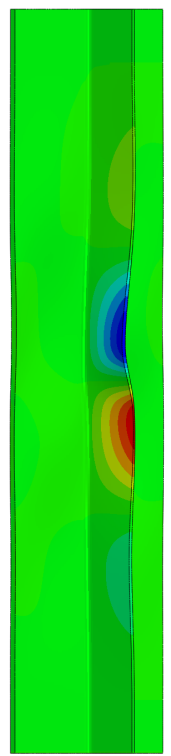

(a) out-ofplane displacement

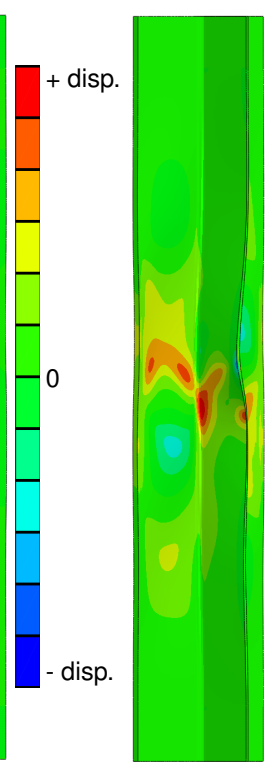

(b) transverse strain

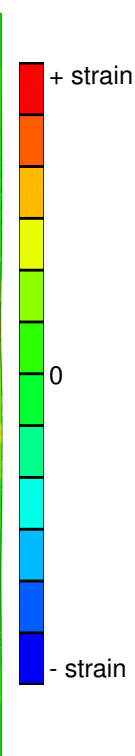

(c) axial
strain

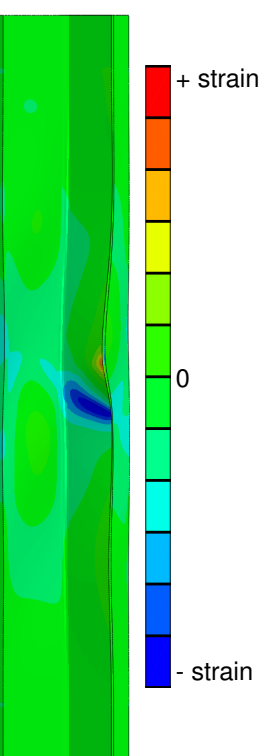

Figure 10. Out-of-plane displacements and strains from 2195 analysis 


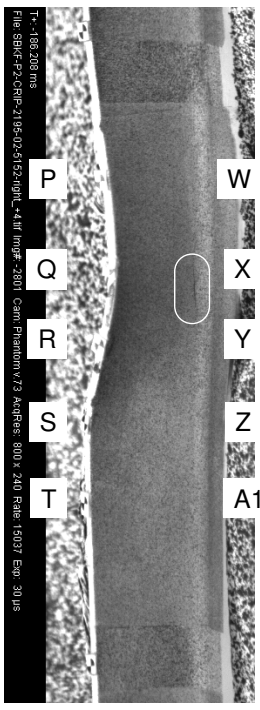

(a) $\mathrm{t}=-186.2 \mathrm{~ms}$

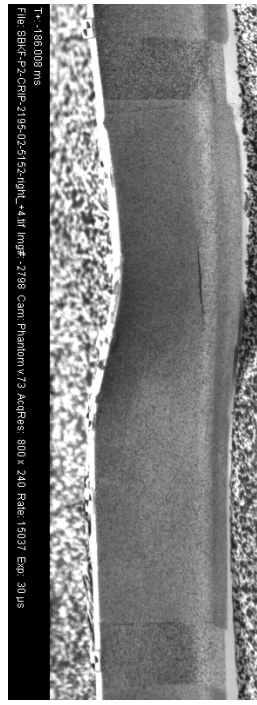

(b) $\mathrm{t}=-186.0 \mathrm{~ms}$

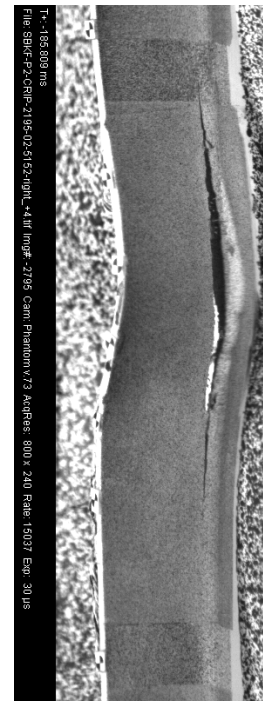

(c) $\mathrm{t}=-185.8 \mathrm{~ms}$

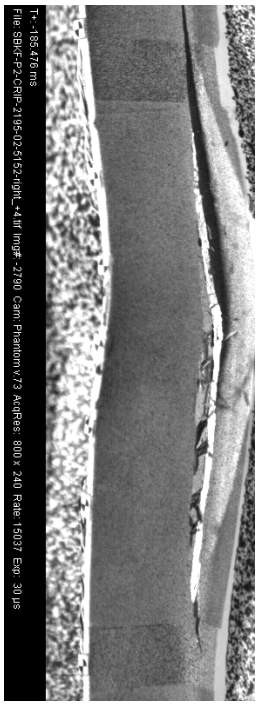

(d) $\mathrm{t}=-185.5 \mathrm{~ms}$

Figure 11. Progression of separation failure in 2195-02

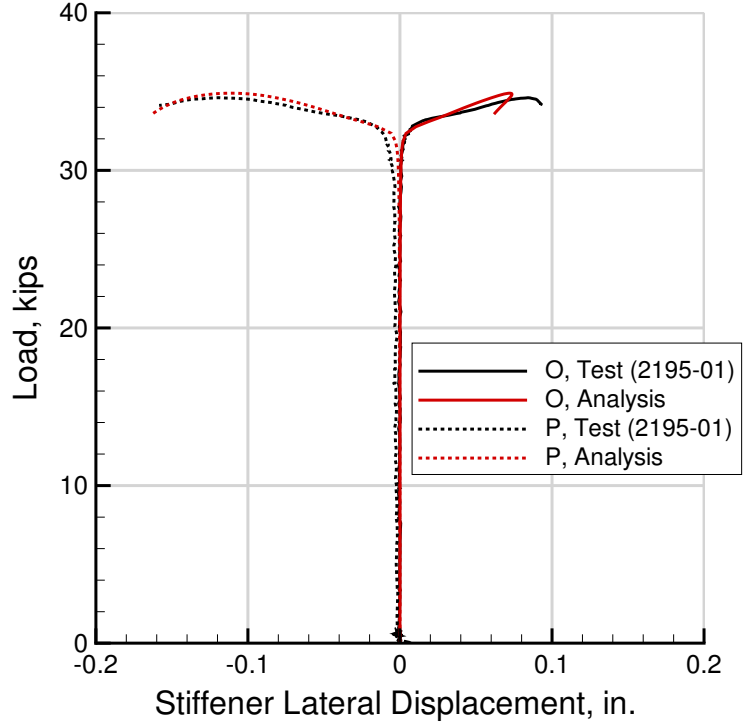

(a) gage locations $\mathrm{O}$ and $\mathrm{P}$

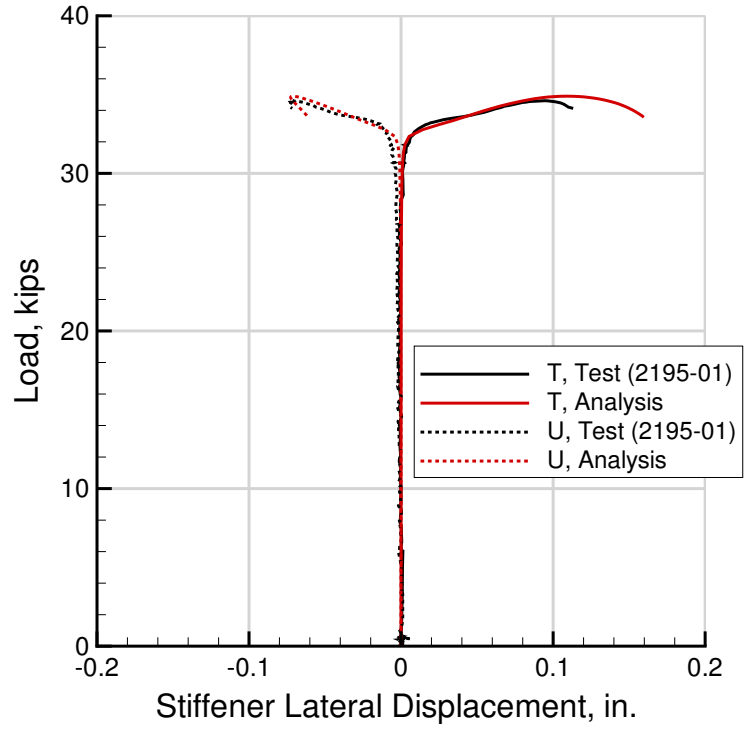

(b) gage locations $\mathrm{T}$ and $\mathrm{U}$

Figure 12. Stiffener lateral displacements for 2195 


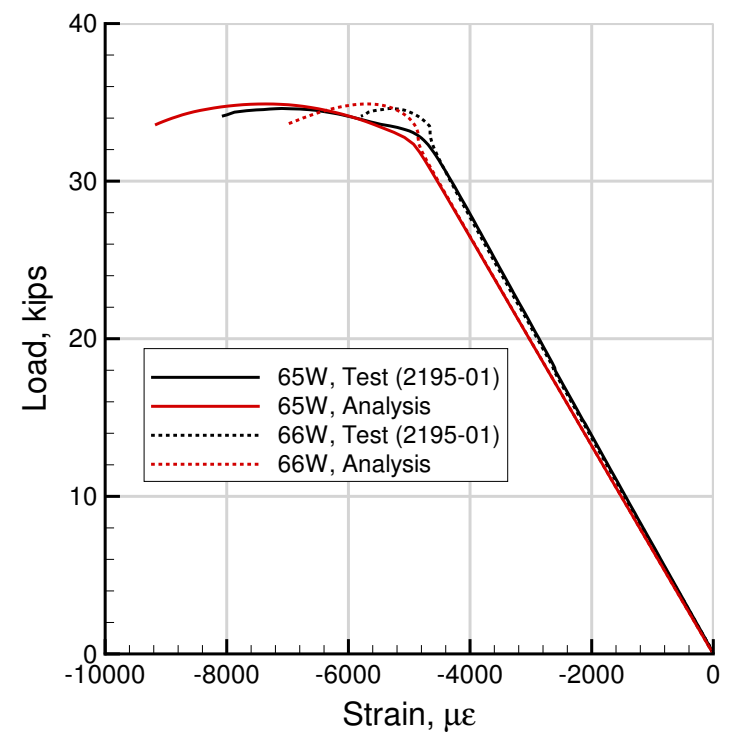

(a) longitudinal strain

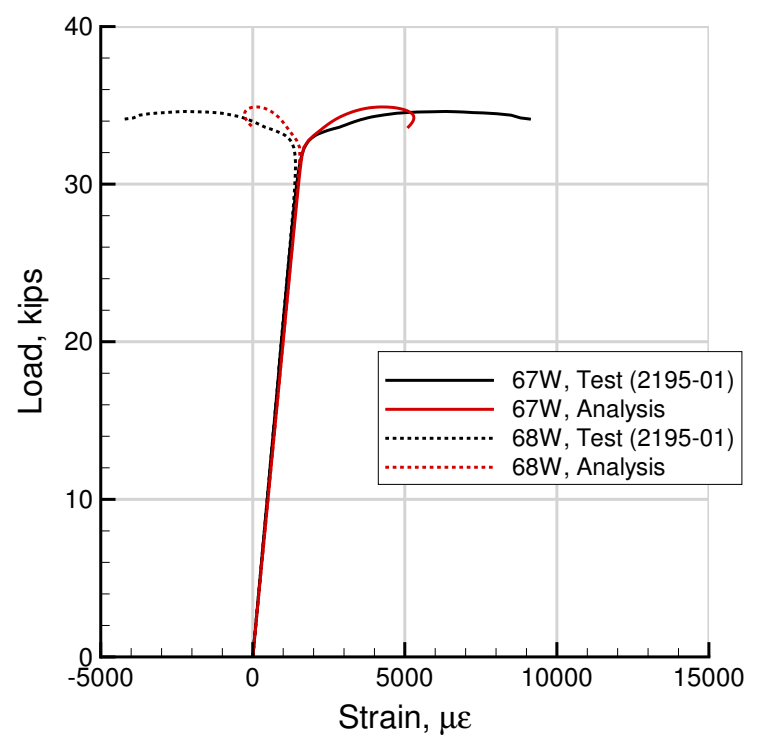

(b) short transverse strain

Figure 13. Strains in the longitudinal and short transverse directions at gage location $\mathrm{W}$

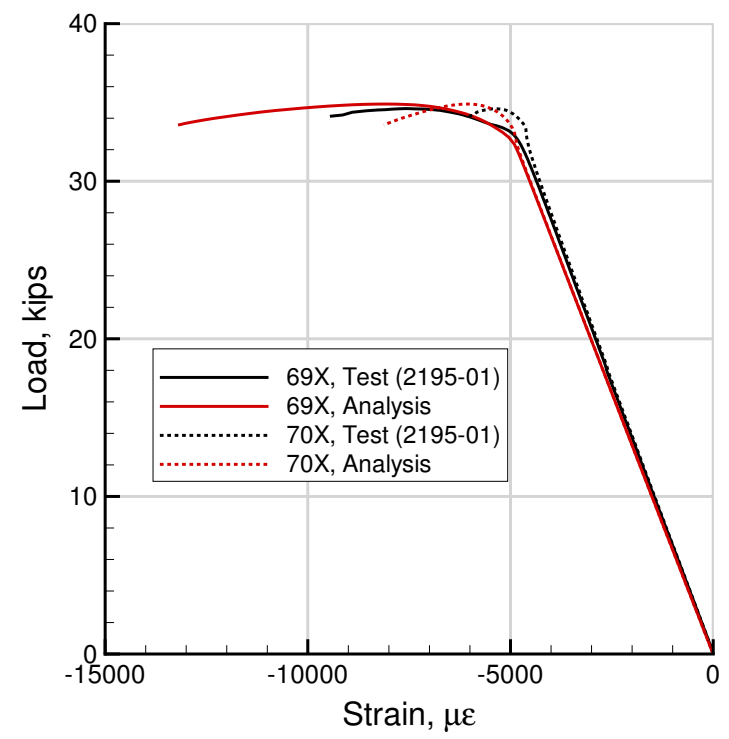

(a) longitudinal strain

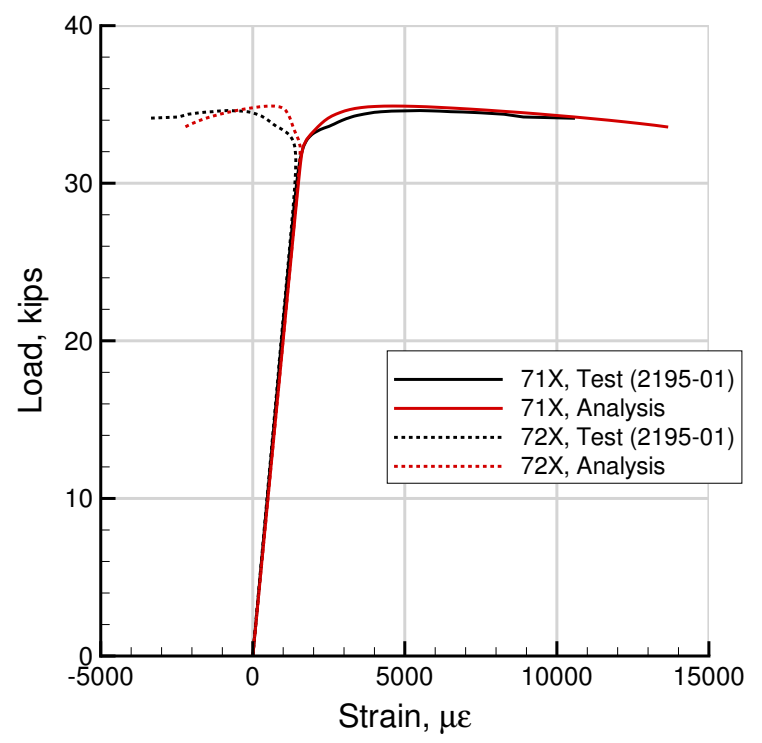

(b) short transverse strain

Figure 14. Strains in the longitudinal and short transverse directions at gage location $\mathrm{X}$ 


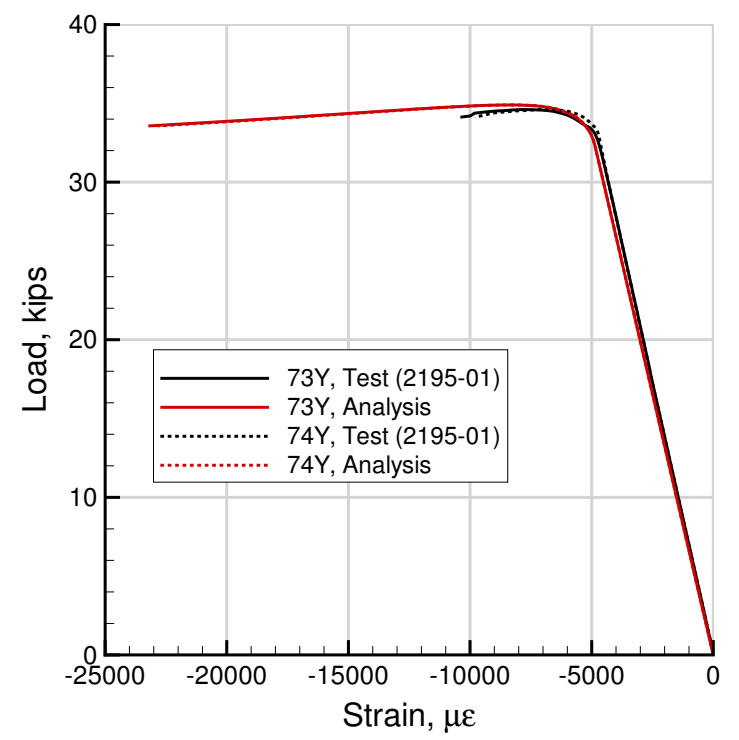

(a) longitudinal strain

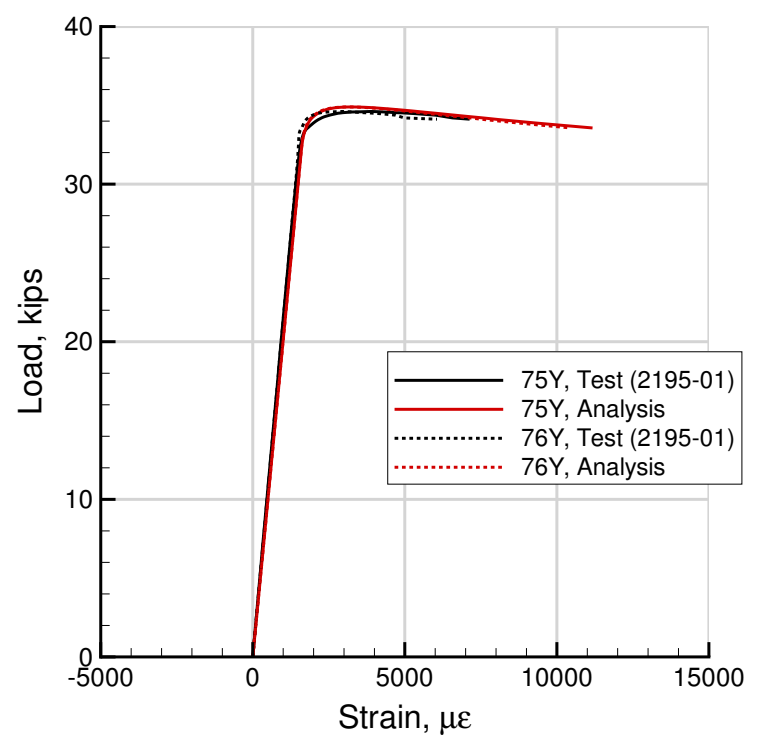

(b) short transverse strain

Figure 15. Strains in the longitudinal and short transverse directions at gage location $\mathrm{Y}$

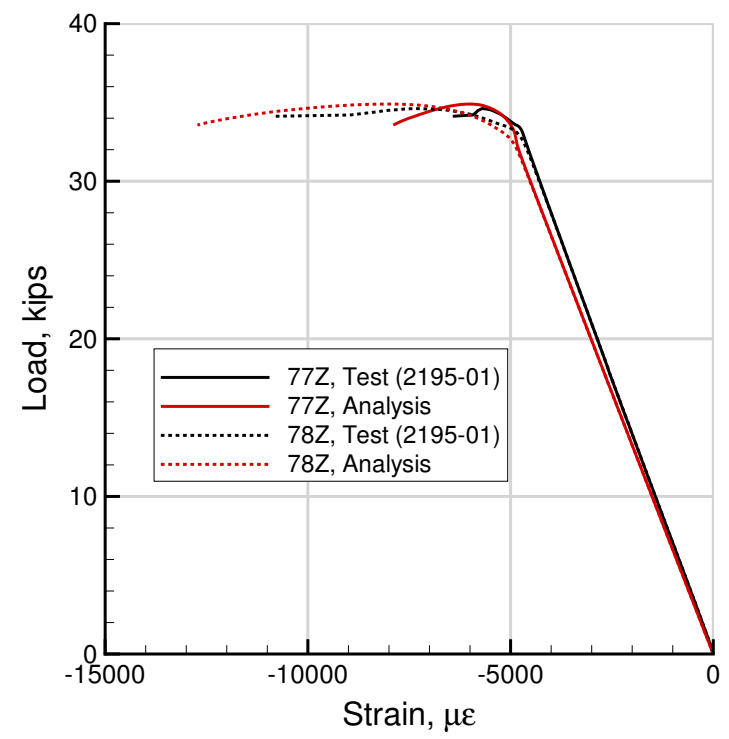

(a) longitudinal strain

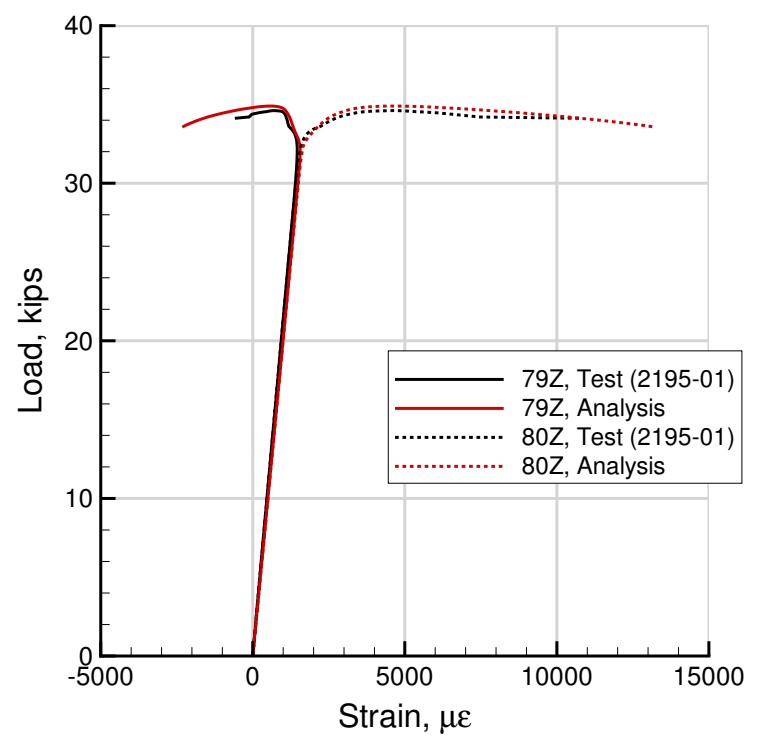

(b) short transverse strain

Figure 16. Strains in the longitudinal and short transverse directions at gage location $\mathrm{Z}$ 


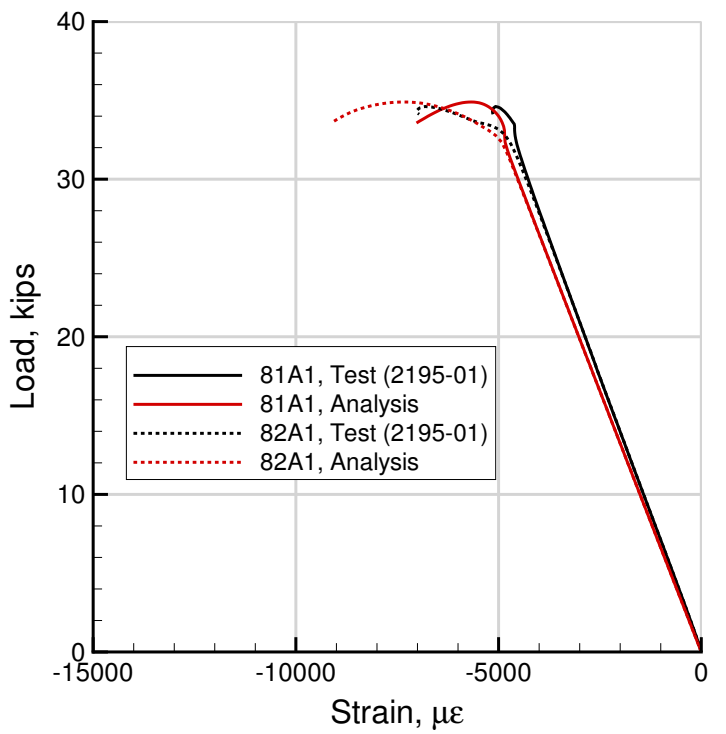

(a) longitudinal strain

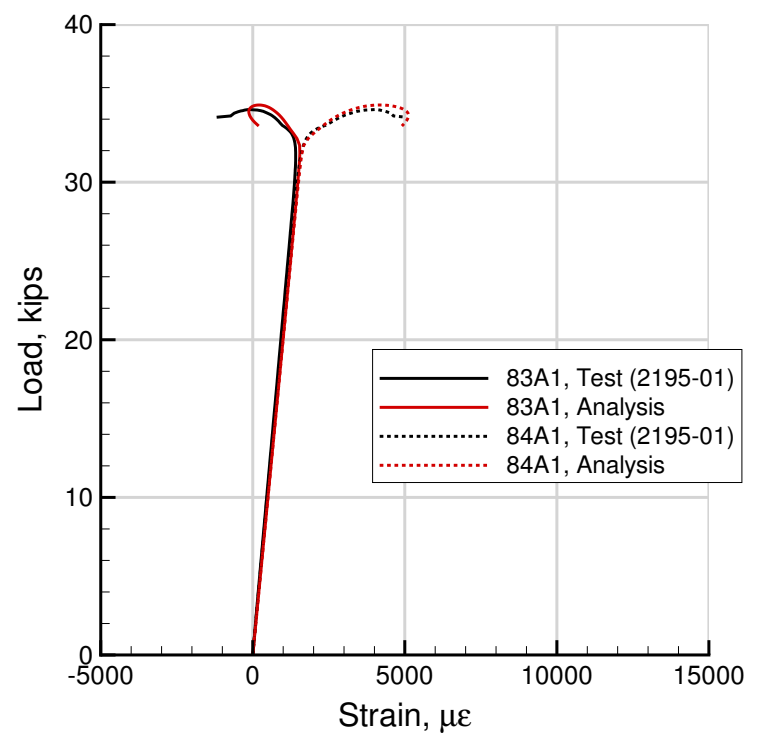

(b) short transverse strain

Figure 17. Strains in the longitudinal and short transverse directions at gage location A1 


\section{B. Al-Li 2050 specimens}

Two Al-Li 2050 specimens were loaded under an axial compressive load, and are denoted as 205001 and 2050-02. The objective of the tests was to continue loading until a separation failure occurred similar as to what was seen in the tests of the Al-Li 2195 specimens; however, during the tests of both Al-Li 2050 specimens, the knife-edge supports came into contact with the potting before any separation failure was observed. Although loading was continued until material failure did occur, the results presented herein use the point at which contact between the knife-edge supports and the potting occurred as the end of the test. Two observations were used to establish the point at which the contact occurred. One, in the postbuckling range of the load-end displacement response, the load started to increase with increasing end displacement, which indicated the knife-edge supports had entered the load path resulting in the increase in stiffness. Two, for the image at which the load started to increase, there did not appear to be any contact between the knife-edge supports and the potting in the images acquired by the DIC systems.

The load-end displacement responses for the two

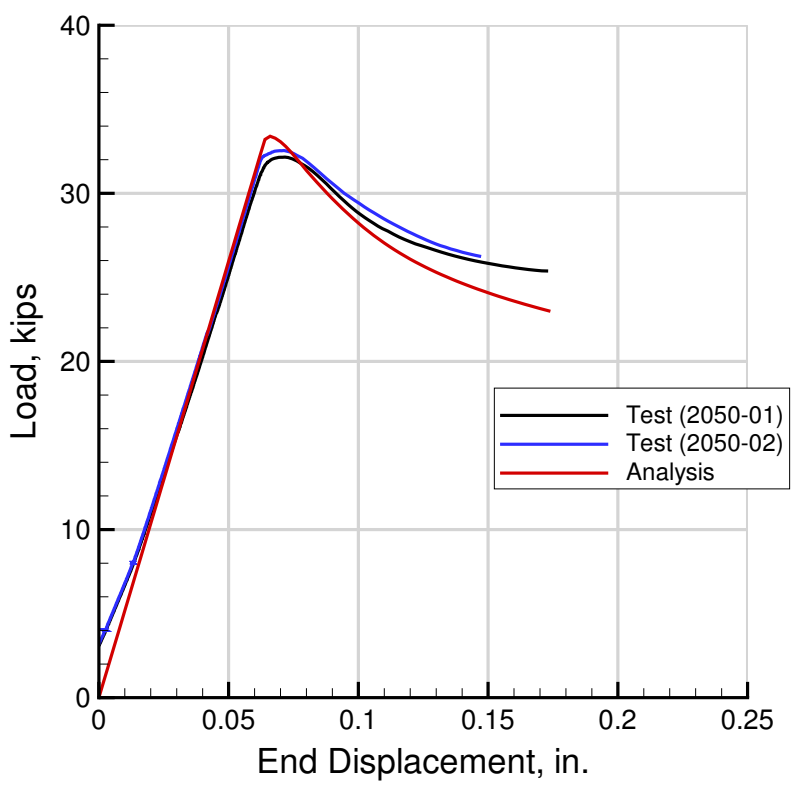

Figure 18. Load vs. end displacement response for 2050 specimens

specimens and the corresponding predicted response are shown in Figure 18. As with the 2195 specimens, the end displacements were adjusted so the slope of the linear portion of the load-end displacement response aligned with the slope from the analysis. The buckling and crippling loads, and load and end displacement at the end of the test are summarized in Table 5. For the specimens, the measured buckling and crippling loads were within $3 \%$ of each other. The measured buckling loads were within $7 \%$ of the predicted buckling load, and the measured crippling loads were within $4 \%$ of the predicted crippling load. The predicted load at an end displacement of $0.174 \mathrm{in}$. was $23.0 \mathrm{kips}$, and for an end displacement of $0.147 \mathrm{in}$. was 24.2 kips. These predicted loads were within $10 \%$ and $8 \%$ of the the loads for $2050-01$ and $2050-02$, respectively. While the difference between specimen load at the end of the test and the predicted loads at the corresponding end displacements was not significant, the predicted slope of the load-end displacement response in the postcrippling range indicates the panel was softening at a faster rate in the analysis than was seen in the specimens. Further analyses are necessary to determine the reason for this behavior, and whether it could lead to a premature prediction of material failure (once a failure criterion is added to the model), and whether it would affect the crippling load.

Table 5. Results from tests and analysis of Al-Li 2050 specimens

\begin{tabular}{|l|c|c|c|}
\hline & $2050-01$ & $2050-02$ & Analysis \\
\hline buckling load, kips & 31.2 & 31.9 & 33.2 \\
\hline crippling load, kips & 32.2 & 32.6 & 33.4 \\
\hline load at end of test, kips & 25.4 & 26.2 & 23.0 \\
\hline end displacement at end of test, in. & 0.173 & 0.147 & 0.174 \\
\hline
\end{tabular}

Full-field out-of-plane displacements of the skin are shown using color contours to represent the buckling mode in Figure 19, and the deformed shape at the end of the test in Figure 20. As with the 2195 tests and analyses, the buckling modes of the skin and stiffener had four half waves along the length, and specimen 2050-02 buckled into a shape with a negative amplitude compared to 2050-01 and the analysis. For the specimens the half waves closer to the top of the test section had larger amplitudes than those near the middle. As the test progressed, the localization of the larger postbuckling displacements toward the top of the test section continued, with the areas of largest deformation occurring slightly above the midlength for 
2050-01. This bias could have resulted from an initial geometric imperfection or nonuniform loading.

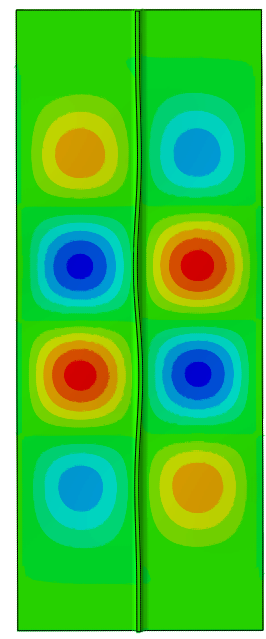

(a) predicted

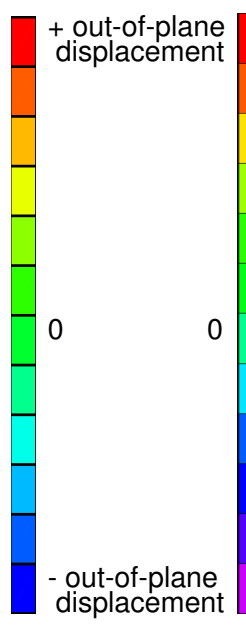

Figure 19. Buckling shapes for 2050

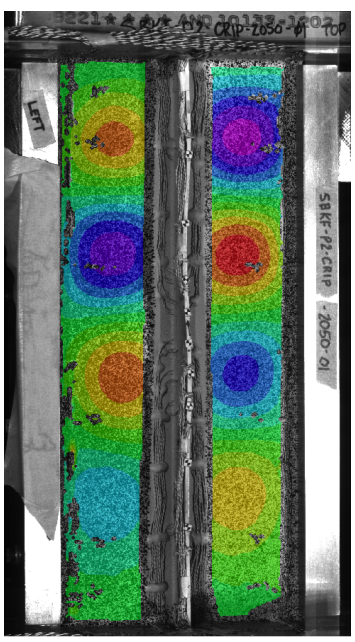

(b) measured, 2050-01

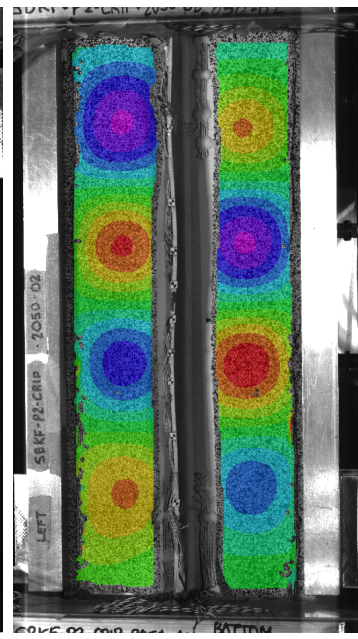

(c) measured, 2050-02

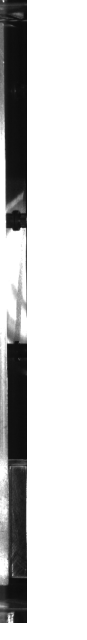

$$
\text { (1) }
$$

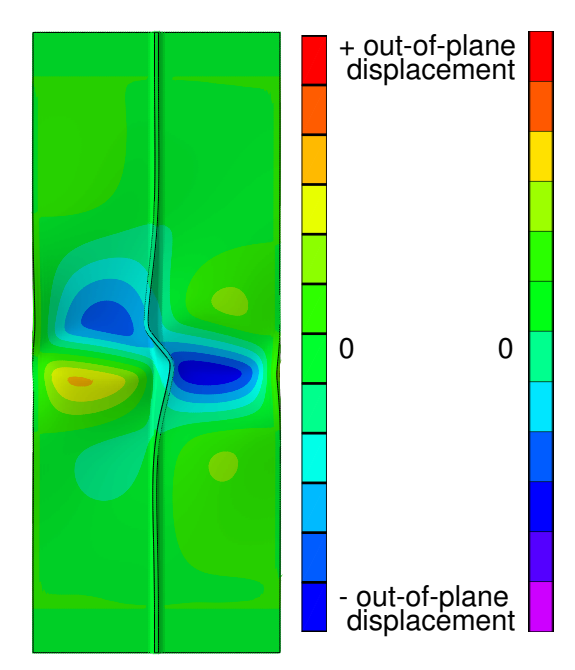

(a) predicted

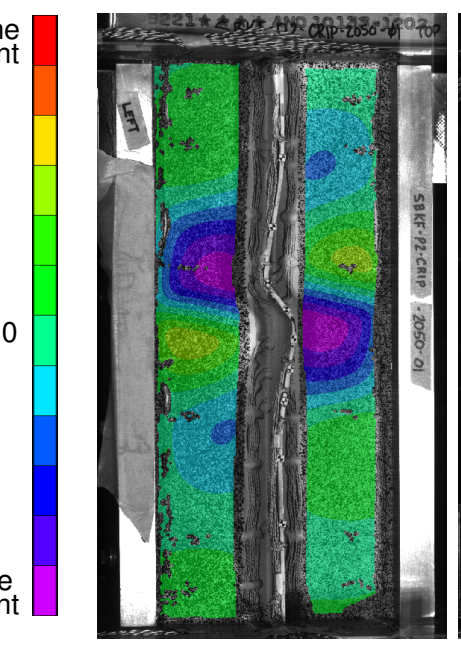

(b) measured, 2050-01

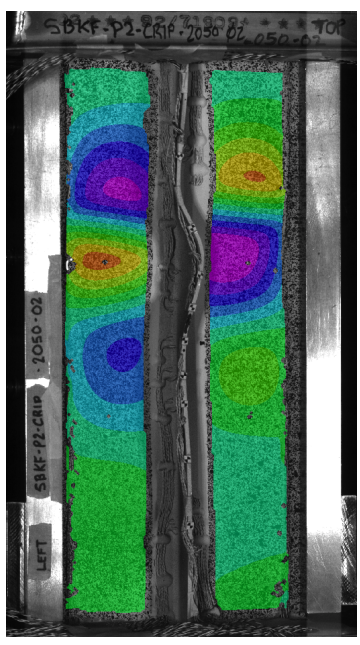

(c) measured, 2050-02

Figure 20. Deformed shapes at end of test for 2050

Full-field measurements of stiffener lateral displacement and the transverse strain at the end of the test are shown in Figure 21. Similar to the 2195 specimens, an area of high tensile strain in the short transverse direction develops in the 2050 specimens. As shown in Figure 21a, the point between the two middle half waves occurred closer to gage location Q, 0.65 in. above the midlength (same axial position as location $\mathrm{X}$ ), than to gage location $\mathrm{R}$ which was at the midlength (same axial position as location $\mathrm{Y}$ ). As a result the areas of high tensile strain were between gage locations $\mathrm{W}$ and $\mathrm{X}$, as shown in Figures 21b and 21c, as opposed to being near location $\mathrm{Y}$ as in the 2195 specimens. These areas were near the base of the stiffener in the region where the fillet radius starts. In the analysis this area was predicted to develop around gage location $\mathrm{Y}$, the midlength of the test section.

Load-stiffener lateral displacement responses at locations O, P, T, and U are shown in Figure 22. Only the measurements for 2050-01 and the predictions are shown. While the response for 2050-02 was similar, the displacement response was opposite and is not shown here for clarity. As seen with the out-of-plane displacements of the skin, the measured stiffener lateral displacements at locations $\mathrm{O}$ and $\mathrm{P}$ (Figure 22a), in the top half of the test section, were greater than at locations $\mathrm{T}$ and $\mathrm{U}$ (Figure 22b), in the bottom half 


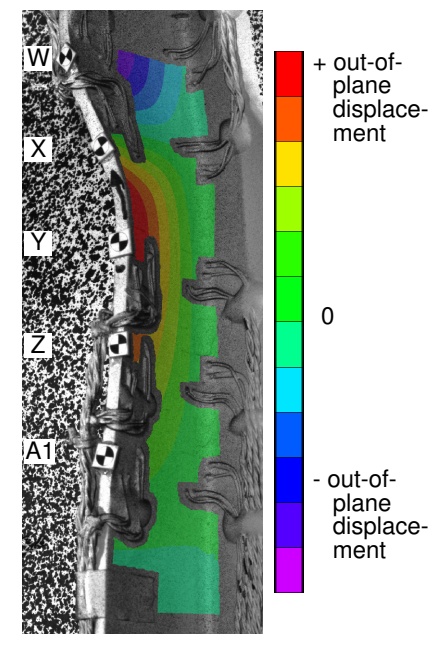

(a) lateral displacement, right side

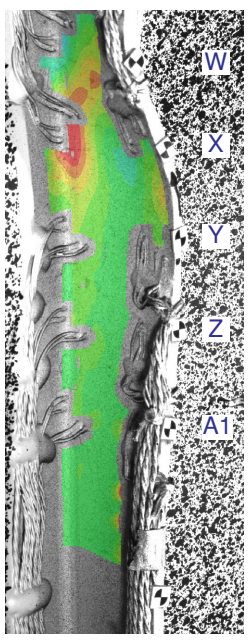

(b) strain, left side

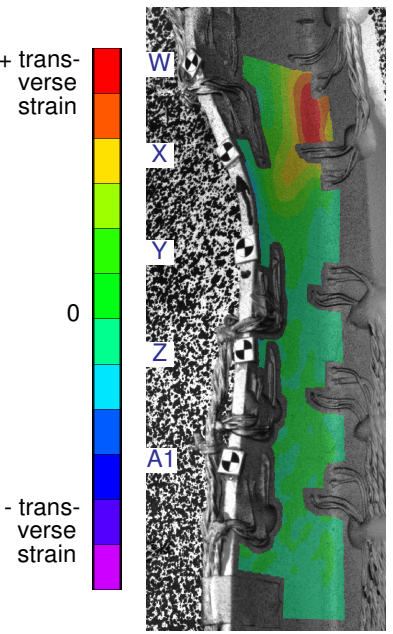

(c) strain, right side

Figure 21. Measurements from local stiffener DIC systems for 2050-01

of the test section. At these points, the characters of the responses of the measurements and predictions were similar, even though the magnitudes of the displacements were significantly different. However due to the differences in the axial location of the areas of greatest deflection in the postbuckling shapes between measurements and prediction, as shown in Figures 19 and 20, differences would be expected.

Load-transverse strain responses at gage locations W, X, Y, Z and A1 are shown in Figure 23 for specimen 2050-01 and the analysis. Strain gages at locations W and X went off-scale in the postbuckling range, and those responses end at the last value before the gages went off-scale in Figures 23a and 23b. There were similarities in the characteristics of the strain responses; however, since the locations of the areas of highest strains developed at different locations in the test and the analysis, the comparisons had to consider the responses at different locations. In general, best agreement was seen when comparing the response of 2050-01 at one gage location to the analysis prediction at the adjacent gage location below. For example, the transverse strains on both sides of the stiffener continue to increase in the postbuckling range for the measurements at location X for 2050-01 (Figure 23b) and the predictions at location Y for the analysis (Figure 23c). For all other strain gage pairs shown in Figure 23, the strains on the left and right sides of the stiffener initially diverge in the postbuckling range. Another example of the agreement between the measured and predicted strains at adjacent locations would be the response at location $Y$ for specimen 205001 (Figure 23c) was similar to the response at location $\mathrm{Z}$ in the analysis (Figure 23d). At these respective locations, in the initial postbuckling range, strains on opposite sides of the stiffener diverged and then after crippling a reversal of strain occurred on both sides of the stiffener.

The development of the deformations in the postcrippling response in the 2050 specimens, was similar to the postcrippling response of the 2195 specimens as would be expected due to the specimens having the same geometry. The main difference between the 2050 specimens and the 2195 specimens was the magnitude of the end displacement at the end of the test. Based on the averages of the end displacements at the ends of the tests, the end displacement at the end of the 2050 tests was $74 \%$ greater than the end displacement at failure for the 2195 specimens. Also, there were no visible cracks at the end of the 2050 tests. So if further testing was conducted with 2050 specimens such that the knife-edge supports did not come in contact with the potting, it would be likely the end displacement when cracks did develop would be even greater than the $74 \%$ increase from the end displacement at failure for the 2195 specimens. Additionally, either the initial imperfection shape or loading imperfections had a greater influence on the 2050 specimens which resulted in the postbuckling shape being biased toward the top of the test section. Including either or both could improve the agreement between test and analysis. 


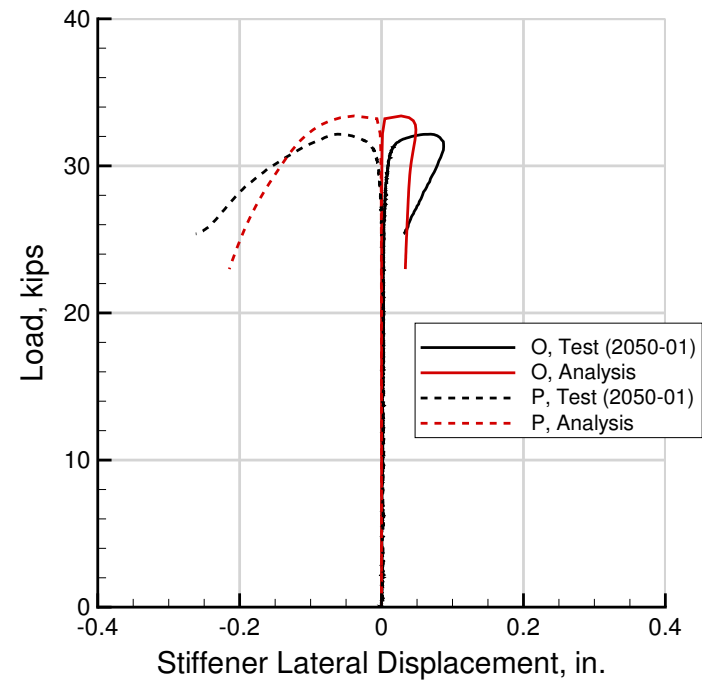

(a) gage locations $\mathrm{O}$ and $\mathrm{P}$

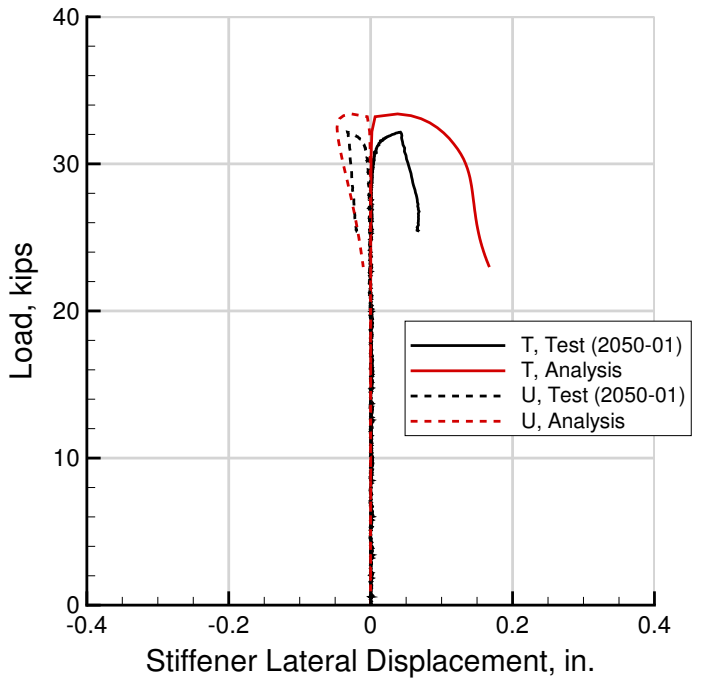

(b) gage locations $\mathrm{T}$ and $\mathrm{U}$

Figure 22. Stiffener lateral displacements for 2050

\section{Concluding Remarks}

Four blade-stiffened panels were tested under axial compression. Two of the panels were fabricated from Al-Li alloy 2195 and two from Al-Li alloy 2050. The buckling, crippling, and postcrippling response was observed for the specimens. A failure characterized by the stiffener separating from the skin was observed for the two 2195 specimens. Strain gages, DIC systems, and high-speed cameras were used to capture the complex strain state leading to the initiation and failure of the specimens. For the 2050 specimens, the knife-edge supports that were used to restrain out-of-plane displacements on the unloaded skin edges came into contact with the potting effectively ending the test before any material failure was observed. Finite element analyses were conducted, and very good agreement was seen between the test results for the 2195 specimens and the analysis when using an isotropic strain hardening material model. The analysis for the 2050 specimens was less conclusive as the postbuckling behavior of the specimens was different than in the analysis. Future work will consider improving the fidelity of the finite element analysis by using a measured imperfection in the analysis instead of the eigenmode imperfection, considering material anisotropy in the yield response, and incorporating a failure criterion into the analysis to try to predict the initiation of the separation failure.

\section{Acknowledgments}

This work was conducted as part of the NASA Engineering and Safety Center (NESC) Shell Buckling Knockdown Factor Project, NESC Assessment \#:07-010-E.

\section{References}

${ }^{1}$ Hafley, R. A., Domack, M. S., Hales, S. J., and Shenoy, R. N., "Evaluation of Aluminum Alloy 2050-T84 Microstructure and Mechanical Properties at Ambient and Cryogenic Temperatures," NASA TP 2011-217163, 2011.

${ }^{2}$ Software Package, MSC.PATRAN 2011, MSC.Software Corporation, Santa Ana, CA, ver 2011.1.0 ed., 2011.

${ }^{3}$ Software Package, Abaqus/Standard, SIMULIA, Providence, RI, ver. 2011.11 .1 ed., 2011.

${ }^{4}$ Hafley, R. A., "Private Communication," Received August 2011. 


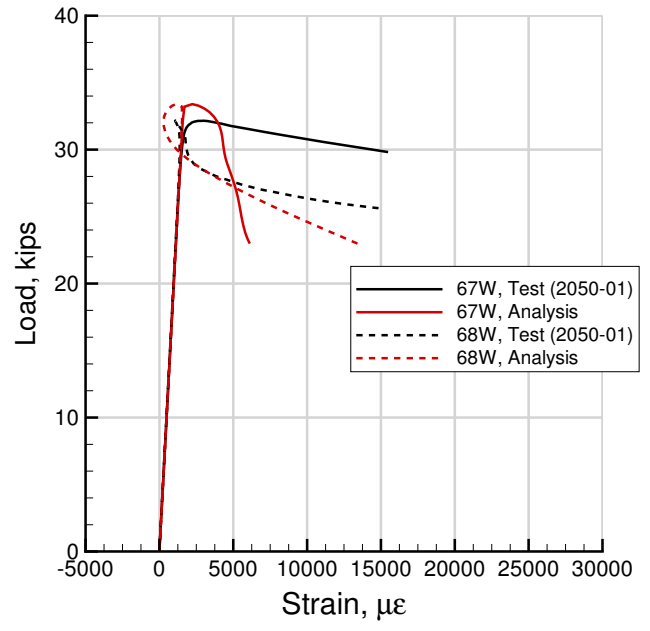

(a) gage location $\mathrm{W}$

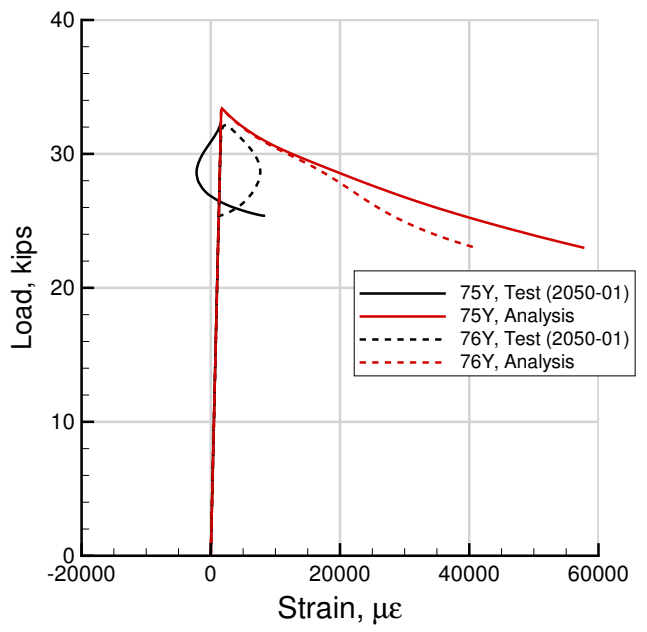

(c) gage location $\mathrm{Y}$

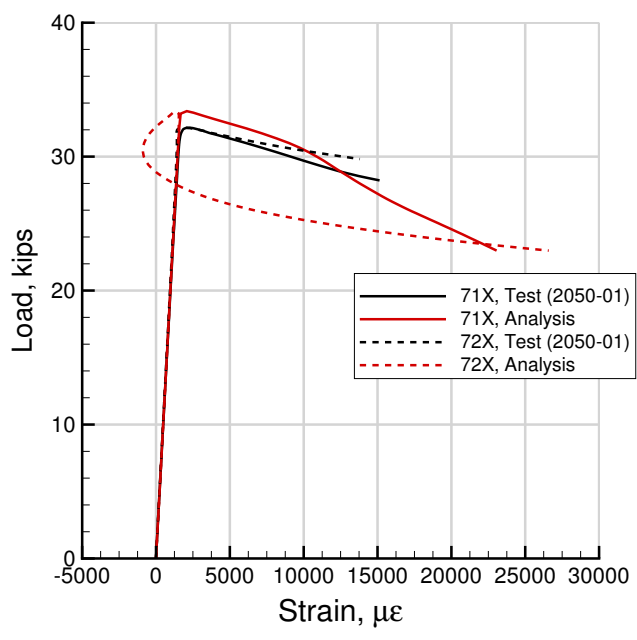

(b) gage location $\mathrm{X}$

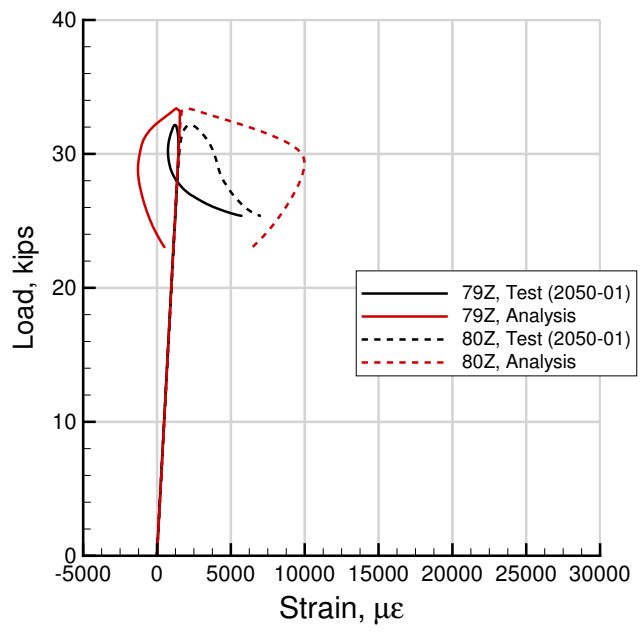

(d) gage location $\mathrm{Z}$

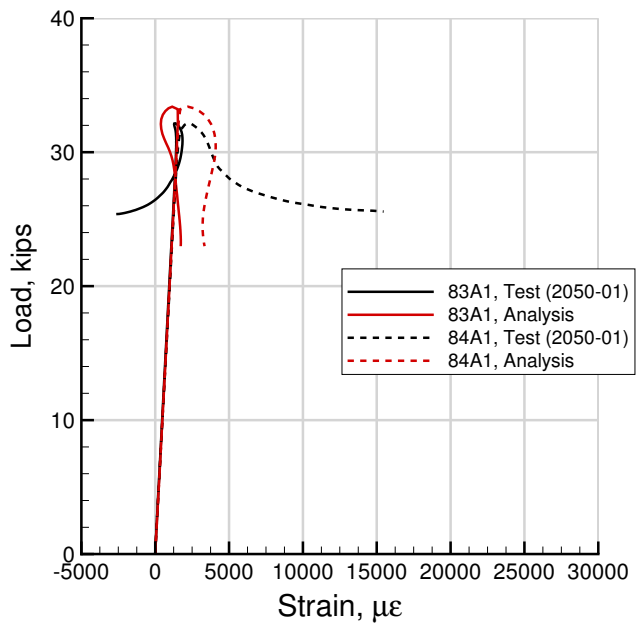

(e) gage location A1

Figure 23. Stiffener transverse strains for 2050-01 and analysis (odd-numbered gages on right side of stiffener, even-numbered gages on left side of stiffener) 